\title{
A chimeric IDD4 repressor constitutively induces immunity in Arabidopsis via the modulation of salicylic- and jasmonic acid homeostasis.
}

\author{
Ronny Völz ${ }^{1,2 *}$, Soon-Kap Kim ${ }^{1}$, Jianing $\mathrm{Mi}^{1}$, Kiruthiga G. Mariappan ${ }^{1}$, Anna Siodmak ${ }^{1}$, Salim Al-Babili , \\ Heribert Hirt1,3, $4^{*}$ \\ ${ }^{1}$ Center for Desert Agriculture, Division of Biological and Environmental Sciences and Engineering, King Abdullah University of \\ Science and Technology, Thuwal 23955-6900, Saudi Arabia \\ ${ }^{2}$ Department of Agricultural Biotechnology, Center for Fungal Genetic Resources and Plant Immunity Research Center, Seoul \\ National University, Seoul 08826, Korea \\ ${ }^{3}$ Institute of Plant Sciences Paris-Saclay IPS2, CNRS, INRA, Université Paris-Sud, Université Evry, Université Paris-Saclay, \\ Bâtiment 630, 91405 Orsay, France \\ ${ }^{4}$ Max Perutz Laboratories, University of Vienna, Vienna, Austria \\ * Correspondence: Ronny.volz@kaust.edu.sa, heribert.hirt@kaust.edu.sa
}

\section{Abstract:}

INDETERMINATE DOMAIN (IDD)/BIRD proteins belong to a highly-conserved plant-specific group of transcription factors with dedicated functions in plant physiology and development. Here, we took advantage of the chimeric repressor gene-silencing technology (CRES-T, SRDX) to widen our view on the role of IDD4/IMPERIAL EAGLE and IDD family members in plant immunity. The hypomorphic idd4SRDX lines are compromised in growth and show a robust auto-immune phenotype. Hormonal measurements revealed the concomitant accumulation of salicylic acid and jasmonic acid suggesting that IDDs are involved in regulating the metabolism of these biotic-stress hormones. The analysis of immunity-pathways showed enhanced activation of immune MAP kinase-signaling pathways, the accumulation of hydrogenperoxide and spontaneous programmed cell-death. The transcriptome of non-elicited idd4SRDX lines can be aligned to approximately $40 \%$ of differentially expressed genes (DEGs) in flg22-treated wild-type plants. The pattern of DEGs implies IDDs as pivotal repressors of flg22-dependent gene induction. Infection experiments showed the increased resistance of idd4SRDX lines to Pseudomonas syringae and Botrytis cinerea implying a function of IDDs in defense adaptation to hemibiotrophs and necrotrophs. Genomewide IDD4 DNA binding studies (DAP-SEQ) combined with DEG analysis of idd4SRDX lines identified IDD4-

(C) The Author(s) 2019. Published by Oxford University Press on behalf of Japanese Society of Plant Physioldgists. All rights reserved. For permissions, please email: journals.permissions@oup.com 
regulated functional gene clusters that contribute to plant growth and development. In summary, we discovered that the expression of idd4SRDX activates a wide range of defense-related-traits opening up the possibility to apply idd $4 S R D X$ as a powerful tool to stimulate innate immunity in engineered crops.

Keywords: Arabidopsis, IDD4, immunity, MAPK, transcription factor, salicylic acid, jasmonic acid

\section{Introduction:}

Plant responses to pathogens require the tight control of immune mechanisms to favor defense on the expense of growth and development. Thus, plants can trigger specific differentiation programs or promote defense strategies instead of growth depending on the pathogenic intruder. Although the molecular mechanisms by which plants integrate environmental and endogenous cues are not entirely understood, there is a high degree of collaboration between the various elements of plant MAP kinase signaling pathways (Marin-de la Rosa et al. 2015). Similar to animals, plants use pattern recognition receptors (PRRs) to rapidly activate defense signaling pathways and immune responses upon pathogen attack (Kaisho and Akira 2006; Zipfel 2008). PRRs and their associated signaling components possess a wide range of similarities in mammals, plants, and invertebrates (Mushegian and Medzhitov 2001; Shiu and Bleecker 2001). Plant immunity relies on the recognition of pathogen-derived molecules to activate pattern-triggered immunity (PTI) and effector-triggered immunity (ETI) (Jones and Dangl 2006). The PTI is initiated after the perception of pathogen-associated molecular patterns (PAMPs) of characteristic pathogen components. FLAGELLIN22 (flg22), a 22 amino acid peptide naturally occurring in bacterial flagella, represents one crucial PAMP to trigger PTI in plants. Flg22 is perceived by the plasma membranelocalized receptor FLAGELLIN-INSENSITIV2 (FLS2) which associates with BRI1-ASSOCIATED RECEPTOR KINASE (BAK1) to rapidly stimulate two mitogen-activated protein kinase (MAPK) cascades. MAPK cascades consist of three sequentially activated kinase modules composed of a MAPK kinase kinase, a MAPK kinase and eventually a MAPK, thereby linking upstream signals to downstream targets. 
Throughout the plant kingdom, the MAPK orthologues of MPK3, MPK4, and MPK6 represent the final step in the two flg22-activated MAP kinase cascades and transmit signals to respective target proteins by phosphorylation (Bigeard et al. 2015; Tsuda and Katagiri 2010). MPK3, MPK4, and MPK6 are required for the comprehensive activation of defense genes (Frei dit Frey et al. 2014). To reset the immune signaling system and readjust the trade-off between growth and defense, the Arabidopsis Ser/Thr phosphatase of type 2C (AP2C1) functions as a stress-signaling repressor and inactivates MPK4 and MPK6 via dephosphosphorylation (Schweighofer et al. 2007). Mutant ap2c1 plants generate higher amounts of jasmonates and show, together with enhanced activation of MAPKs, an elevated resistance against phytophagous mites (Tetranychus urticae) (Schweighofer et al. 2007). By contrast, overexpression of AP2C1 hampers the flg22-induced phosphorylation of MPK3 and MPK6 as well as the ethylene (ET) production and increases the susceptibility to Botrytis cinerea (Galletti et al. 2011).

The three immune phytohormones salicylic acid (SA), jasmonic acid (JA) and ET are the canonical immunity agents that coordinate defense depending on the sort of biotic threat. SA biosynthesis and signaling are induced after direct exposure to a wide range of biotrophic pathogens such as the oomycete Hyaloperonospora arabidopsidis and hemibiotrophic pathogens, like Pseudomonas syringae, while JA and ET signaling are generally important for immunity against necrotrophs including the fungal pathogen Alternaria brassicicola (Li et al. 2019). SA plays a crucial role in local and systemic acquired resistance (Chen et al. 1993). Recent studies have shown that SA signaling is an integral part of PTI and ETI (Chen et al. 1993; Dempsey and Klessig 1994; Durrant and Dong 2004; Gaffney et al. 1993). Furthermore, SA contributes to stomatal immunity upon flg22 perception by FLS2, which results in the stomatal closure in order to avoid the entry of bacterial invaders (Song 2006; Zeng and He 2010). Pathogen-induced SA biosynthesis mainly takes place in chloroplasts by ISOCHORISMATE SYNTHASE 1 (ICS1) (Strawn et al. 2007; Wildermuth et al. 2001). Several transcription factors (TFs) have been reported to be directly recruited to the ICS1 promoter in order to regulate ICS1 expression, such as the two closely related pathogen-induced 
TFS SYSTEMIC ACQUIRED RESISTANCE DEFICIENT 1 (SARD1) and CALMODULIN-BINDING PROTEIN 60g (CBP60g) which are essential for ICS1 induction and SA accumulation after pathogen perception (Wang et al. 2011; Zhang et al. 2010). In sard1 cbp60g double mutants, ICS1 expression is not induced, SA biosynthesis is interrupted, and plants are more susceptible to Psm ES4326 whereby SARD1 overexpression results in constitutive activation of defense responses and increased SA levels (Zhang et al. 2010). SARD1 and CBP60g modulate the expression of signaling components of PTI and contribute to flg22-induced resistance to Pst DC3000 (Sun et al. 2015). The WRKY family members WRKY28 and WRKY46 have also been shown to promote induction of ICS1, partly in complex with SARD1 (van Verk et al. 2011; Wang et al. 2015). A hub in SA signaling is formed by NON-EXPRESSOR OF PATHOGENESIS-RELATED GENES 1 (NPR1) and its paralogs NPR3 and NPR4 (Cao et al. 1994; Cao et al. 1997; Fu et al. 2012; Kuai et al. 2015; Zhang and Cai 2005). These factors act as SA receptors (Canet et al. 2010; Fu et al. 2012; Manohar et al. 2014; Wu et al. 2012), whose function is mediated by members of the TGA family (Despres et al. 2000; Zhou et al. 2000), TCP transcription factors (Li et al. 2018) and by the NIM1-INTERACTING (NIMIN) proteins (Hermann et al. 2013). However, NPR1 and NPR3/4 exert opposite transcriptional regulation on plant immunity in a SA-dependent manner (Ding et al. 2018). Several studies demonstrated that the SA signaling pathway predominantly acts antagonistically to JA-mediated signaling (Robert-Seilaniantz et al. 2011; Van der Does et al. 2013). In general, these tradeoffs are confined to the tissues adjacent to the infection sites, and systemic tissues are omitted (Spoel et al. 2007).

The phytohormones JA and Gibberellin (GA) regulate the signal integration at the growth-defense conjunction and coordinate the allocation of resources to balance the metabolic cost in an environmentdependent manner. GA influences plant growth and defense by targeting for degradation a class of GAcontrolled inhibitory proteins called DELLAs (Cheng et al. 2004; Dill et al. 2001). DELLAs can act as key negative regulatory switches at the junction of growth and defense by simultaneously integrating light and JA signals (Daviere and Achard 2013; Navarro et al. 2008). JA positively regulates defense response 
by controlling JASMONATE-ZIM-DOMAIN PROTEIN (JAZ) protein degradation to promote JASMONATE INSENSITIVE 1 (MYC2)-controlled transcription (Chini et al. 2007; Fernandez-Calvo et al. 2011; Niu et al. 2011; Zhang et al. 2015). The transcriptional hub composed of PHYTOCHROME-INTERACTING FACTORS (PIFs), DELLA, JAZ, and MYC2 negotiate the growth-defense trade-off in dependence on the environmental condition and biotic stresses, like the perception of a pathogen (Smakowska et al. 2016). Auxin, JA, GA, and brassinosteroids, as well as abiotic stimuli like light-intensity and temperature, modulate the activity of the helix-loop-helix TF PIF4 (Gangappa et al. 2017). PIF4 acts as a positive regulator of cell elongation and stem growth but suppressor of immunity (Choi and Oh 2016; Leivar and Monte 2014; Oh et al. 2012; Yamashino et al. 2013). Furthermore, PIF4 transcriptionally regulates biosynthesis and signaling genes of auxin (Franklin et al. 2011; Sun et al. 2013), the central hormone for growth and differentiation (Bhatia et al. 2016; Ljung 2013; Schlereth et al. 2010) and ethylene (Sakuraba et al. 2014) which conditionally contributes both to particular defense reactions and tissue differentiation programs (Pre et al. 2008). Previous studies have shown that DELLAs can interact with PIFs, JAZ and MYC in a stress-dependent manner while JAZ interacts with MYC (Li et al. 2016). The increase in GA concentrations leads to the degradation of DELLAs (Murase et al. 2008), which triggers the dissociation of PIFs, JAZ, and MYCs. PIFs bind on their target promoters to activate the expression of genes for optimal GA-regulated growth and development (Marin-de la Rosa et al. 2015; Oh et al. 2012). Meanwhile, JAZs sequester MYC proteins to block their DNA binding and transcriptional activities to inhibit defense-related processes (Melotto et al. 2008). In this way, plants weight GA signals to promote growth over defense. However, when a plant perceives pathogens in their ambient environment, then JA levels increase, which, in turn, leads to the degradation of JAZs, which triggers the dissociation of DELLAs, PIFs, and MYCs. MYCs bind at their target promoters to activate the expression of genes required for JA-regulated defense. In the meanwhile, the sequestration and degradation of PIFs by DELLAs prevent the unfolding of GA-controlled growth programs 
(Zheng et al. 2016). Thus, plants prioritize defense over growth by integrating JA signals (Huot et al. 2014; Smakowska et al. 2016).

The INDETERMINATE DOMAIN (IDD)/BIRD family of plant-specific transcription factors is highly conserved in both monocots and dicots (Colasanti et al. 2006). The high degree of sequence similarity amongst all IDD genes from Arabidopsis, Oryza sativa and Zea mays suggest that they are derived from a common ancestor (Colasanti et al. 2006). To date, at least 16 IDD genes have been found in the Arabidopsis genome $(A t / D D), 15$ in the Oryza sativa genome (Os/DD) and 21 in the Zea mays genome (Zm/DD).

In Arabidopsis, each of the IDDs contains a conserved N-terminal ID domain composed of four zinc fingers (ZFs) and a long sequence for protein interactions (Colasanti et al. 2006; Yoshida et al. 2014). The four ZFs can be subdivided into the $\mathrm{C}_{2} \mathrm{H}_{2}$ type ZF1 and ZF2, which are assigned to DNA interaction, and the $\mathrm{C}_{2} \mathrm{HC}$ type ZF3 and ZF4, which are essential for the interaction of IDD3/MAGPIE and IDD10/JACKDAW with the transcription factors SHORT-ROOT (SHR) and SCARECROW (SCR) (Hirano et al. 2017). IDDs have been assigned to function in multiple developmental processes. In monocots, the maize INDETERMINATE1 (ID1) (Colasanti et al. 2006; Coneva et al. 2007) and the rice Ehd2 (Matsubara et al. 2008) act as key regulators of flowering time. In Arabidopsis, IDD8 regulates photoperiodic flowering by modulating sugar transport and metabolism (Jeong et al. 2015; Seo et al. 2011b). Furthermore, it was reported that IDD3, IDD4, IDD6, IDD8, and IDD10 organize and are expressed in the root ground tissue thereby coordinating the differentiation of the endodermis initial stem cell niche in order to give rise to cortex and endodermis cells (Long et al. 2015; Moreno-Risueno et al. 2015; Yoshida et al. 2014). So far, it was reported that IDD4, IDD5 are expressed in the root ground tissue of the basal meristem. IDD1 promotes the transition to germination by regulating light and hormonal signaling during seed maturation (Feurtado et al. 2011). In a distant subclade of the IDD taxonomy IDD14, IDD15 and IDD16 mutually regulate lateral organ morphogenesis and gravitropism by supporting auxin biosynthesis and transport (Cui et al. 2013). Moreover, two splice variants of IDD14 competitively form nonfunctional heterodimers which may 
regulate starch metabolism (Seo et al. 2011a). Intriguingly, the IDD family members 2, 3, 4, 5, 9 and 10 serve as transcriptional scaffolds to enable transactivation activity of the gibberellin-inhibitor DELLA/RGA proteins in association with the transcriptional regulator SCARCROW-like 3 (SCL3) (Fukazawa et al. 2014; Yoshida et al. 2014; Yoshida and Ueguchi-Tanaka 2014).

In order to overcome the redundancy problem of TF family members and to generate multiple-geneknockdown mutants, the chimeric repressor gene-silencing technology (CRES-T) was developed (Hiratsu et al. 2003). The CRES-T system has been widely used in functional studies in plants (Mahfouz et al. 2012; Oh et al. 2014; Volz et al. 2013), generating a chimeric repressor by the fusion of a transcription factor to a modified ERF-associated amphiphilic repression-(EAR)-motif as plant-specific repression domain (SRDX). The EAR motif was previously identified as a repressor domain in plants. The core sequence consists of only six amino acids (aa) which following the conserved order LXLXLX (X can be any aa) in various plant TFs. The dominant-SRDX peptide (LDLDLELRLGFA) bears the conserved EAR-motif core sequence and was studied on the imposed repressive-dominate effect on transcriptional activators (Hiratsu et al. 2003). The fusion of this amphiphilic peptide is sufficient to turn a transcriptional activator into a strong repressor (Hiratsu et al. 2003; Hiratsu et al. 2004). The exact mode of action depends on the corresponding TF serving as DNA-binding module for the amphiphilic repressor and might involve the association of corepressors. In general, the fusion protein dominantly suppresses the expression of target genes over the activity of the endogenous and functionally redundant transcription factors (Mitsuda and Ohme-Takagi 2009). The TF-SRDX fusion protein binds to the cis-regulatory elements in the promoter sequences of target genes. However, the transcriptional activity is suppressed, and the failure in target gene expression cannot be complemented by redundant proteins since corresponding promoter elements are occupied by the chimeric TF-SRDX protein. It was reported that transgenic plants expressing the SRDX fused to a transcriptional activator exhibit phenotypes likewise to those of the corresponding loss-of-function mutant but unlike to plants that overexpress the factor itself. In accordance with this finding, the fusion 
of SRDX to ETHYLENE-INSENSITIVE 3 (EIN3) converts this central factor in the ethylene signaling cascade into a dominant repressor thereby resulting in an ethylene-insensitive phenotype corresponding to the allelic ein3-1 mutant (Volz et al. 2013). The usage of CRES-T to studying IDD function in plant physiology has been demonstrated previously. A repressive effect of SRDX linked on IDD3 was shown in the regulation of GA signaling pathways (Yoshida et al. 2014). The IDD3SRDX plants exhibit a dwarf-like phenotype with smaller leaves and shorter roots and show a delay in flowering initiation thereby mimicking the phenotype of a GA-signaling and-deficient mutant.

In this study, we report on the expression of the chimeric idd4SRDX construct in Arabidopsis. We show that the expression globally alters the transcriptome composition towards an activated immune system and immune MAP kinase signaling pathways, while factors that promote growth and development are repressed. Furthermore, in accordance with hormonal measurements, pivotal factors that coordinate SA and JA metabolism are supported. idd4SRDX lines show an elevated resistance to Pseudomonas syringae and Botrytis cinerea suggesting that the canonical antagonistic nature of SA vs. JA in defense adaptation to hemibiotrophs and necrotrophs is bypassed by IDD4SRDX expression.

\section{Results:}

\section{Dominant-negative IDD4 constitutively activates innate immunity without bacterial infection}

We sought to find new players involved in the regulation of innate immunity and the coordination of defense hormone homeostasis. Therefore, we generated dominant-negative versions of transcription factors that were previously introduced as positive regulators of abiotic stress response and coordinators of plant development. One of the candidate genes that emerged from this study was IDD4. We took advantage of the chimeric repressor gene-silencing technology (CRES-T) and linked IDD4 with the ERF- 
associated amphiphilic repression-(EAR)-motif (SRDX). The expression of idd4SRDX under the control of the UBIQUITIN10 promoter in WT plants showed a striking phenotype in 19 out of 23 T1 plants, with a reduced fresh and dry weight and plant size (Figure 1A, S1A-B). Two representative lines idd4SRDX1 and idd4SRDX2 were selected to analyze the phenotype in more detail. Notably, non-elicited idd4SRDX lines form aberrant lesions on leaf surfaces, reminiscent of a hypersensitive response reaction to avoid pathogen spreading in leaf tissues (Figure 1B). In order to evaluate the lesion phenotype, 3,3'diaminobenzidine (DAB) staining was performed on non-elicited plants to detect the reactive oxygen species $\mathrm{H}_{2} \mathrm{O}_{2}$ and lactophenol trypan blue (LTB) staining to examine the live/dead cell ratio in leaves. After DAB staining, untreated idd4SRDX lines showed elevated basal hydrogen-peroxide levels, especially in the lesion-forming areas (Figure 1C). This staining correlated with strong LTB staining (Figure 1D) which is indicative of cell death and lesion formation. ROS production and release are among the first immune responses to the sensing of PAMPs and are a benchmark for the strength of the plant defense reactions. Therefore, we evaluated the ROS burst after PAMP perception. The idd4SRDX lines showed already much higher ROS levels than WT at 1 min after flg22 application, and the levels of ROS release could not be increased further (Figure 1H, S1D). In this regard, the ROS burst 10 min after the application was still twofold higher in the two independent idd4SRDX lines, but lower than at the very beginning of the measurements.

Another plant strategy to avoid pathogen infection is the deposition of callose at the respective infection sites. Without flg22-treatment and under sterile conditions on sugar-free MS medium, idd4SRDX lines exhibited spontaneous callose depositions on the leaf surfaces (Figure 1E, S1C). Moreover, a number of innate immunity and PTI-marker genes such as FLG22-INDUCED RECEPTOR-LIKE KINASE 1 (FRK1) (Asai et al. 2002), WRKY33 (Mao et al. 2011), WRKY22 (Asai et al. 2002) and PATHOGENICITY-RELATED FACTORS PR2 (Petersen et al. 2000) were consistently expressed at higher levels in the idd4SRDX lines without pathogen infection (Figure 1 $\mathbf{J}, \mathbf{K}$ ). The expression of these genes demonstrates an auto-immune activated 
transcriptome in idd4SRDX plants. Stomata are entry points of pathogens and are under tight control mediated by the stomatal immunity response (Melotto et al. 2006). Stomatal closure in response to pathogens is mediated by salicylic acid (SA) (Montillet and Hirt 2013) and is counteracted by the bacterial toxin coronatine that provokes the reopening of the stomata in order to facilitate the access of the bacterial intruders (Abulfaraj et al. 2018; Zheng et al. 2012). The question of the stomatal response in idd4SRDX lines is an interesting aspect that might affect the bacterial invasion. Therefore, we analyzed the stomatal aperture at $1 \mathrm{~h}$ and $4 \mathrm{~h}$ after bacterial infection by using the hemibiotrophic pathogen PstDC3000. Interestingly, in the absence of infection, the stomatal aperture in idd4SRDX lines was already reduced when compared to WT plants (Figure 1F-G). However, $1 \mathrm{hr}$ after pathogen perception, the stomata in idd4SRDX and WT are consistently closed as part of the stomata immune response. Intriguingly, $4 \mathrm{hrs}$ after infection, the bacterial strategy to reopen the stomata by the release of the polyketide toxin coronatine does not efficiently reopen the stomata in idd4SRDX when compared to WT. The compromised reopening process might help to prevent effective colonization of the idd4SRDX plants.

To evaluate whether the MAP kinase signaling cascades are affected in the idd4SRDX lines, we analyzed their activation after flg22-application in comparison to WT and GFP:IDD4 lines (IDD4ox). The expression of the GFP:IDD4 fusion construct is driven by the UBIQUITIN10 promoter. MAPK activation was assessed by $\mathrm{pTpY}$ antibody-based immunoprecipitation that targets the phosphorylated MAPKs. Before PAMPperception, MPK3 and 6 activations (at $0 \mathrm{~min}$ ) were below the detection levels in WT, idd4SRDX and IDD4ox lines. However, already $5 \mathrm{~min}$ after flg22-treatment in idd4SRDX, MPK3 and 6 were much more strongly activated than in WT and IDD4ox plants (Figure 1I). The distinct activation of MPK3 and 6 in the idd4SRDX line suggests a function of IDD4 in the regulation of the flg22-induced MAP kinase signaling cascade. Intriguingly, our findings show that particular defense-reactions in idd4SRDX such as the MAP kinase-activation and the stomatal immune response (Fig.1G) are exclusively triggered by PAMP/ pathogen-perception in idd4SRDX plants and thus cannot be considered as an auto-immune phenotype 
per se. All in all, the high ROS levels together with the lesion phenotype, the up-regulation of PTI marker genes, the callose deposition and the reduced stomatal aperture, indicate a constitutive activation of defense responses in idd4SRDX and suggest a role of IDD4 and redundant family members as inhibitors of defense in the absence of a pathogenic challenge.

\section{Salicylic acid levels are significantly elevated in idd4SRDX}

Innate immunity of plants is controlled by a complicated hormonal regulatory network involving the phytohormones SA, jasmonic acid (JA) and ethylene. Depending on the biotic challenge, synergistic and antagonistic interactions between these stress hormones coordinate an adequate immune response. First, we analyzed the free SA levels in 14 day-old plants grown on sugar-free MS medium. idd4SRDX lines 1 and 2 showed a massive increase of SA in comparison to WT (Figure 2A). To evaluate the high SA levels at the molecular level, we analyzed the expression of genes involved in SA-metabolism and signaling. The level of ICS1 (Wildermuth et al. 2001) which encodes an enzyme catalyzing the rate-limiting step in the SA biosynthesis is strikingly increased as well as its transcriptional activator SARD1 (Sun et al. 2015; Wang et al. 2011) (Figure 2B). Furthermore, WRKY28 (Figure 2B) and WRKY46 (Figure 2C) that mutually contribute to SA biosynthesis (van Verk et al. 2011), and WRKY38 (Figure 2C) (Xie et al. 2010), involved in SA perception, are up-regulated. The high SA levels in idd4SRDX lines are also accompanied by the differential expression of genes involved in the SA catabolism. One of the SA catabolism genes is SA 3hydroxylase (S3H). S3H is up-regulated in idd4SRDX lines (Figure $\mathbf{2 B}$ ) and readily inducible after $6 \mathrm{~h}$ of SA treatment with similar expressions patterns like PR1 (Zhang et al. 2013). The S3H enzyme converts SA to 2,3-dihydroxybenzoic acid (2,3-DHBA) in vivo and to 2,5-DHBA in vitro, and both compounds are considered as precursors of SA's major storage form 2,3-DHBA sugar conjugates. The up-regulation of S3H corresponds to an accumulation of 2,3-DHBA sugar conjugates, which was recently shown to be enriched in infected or aged Arabidopsis leaves (Bartsch et al. 2010). The elevated SA levels in idd4SRDX lines 
demonstrate a function of IDD4 in the regulation of SA biosynthesis to avoid SA-dependent defense response activation in the absence of a pathogen.

\section{Jasmonic acid homeostasis is elevated in idd4SRDX}

In addition to SA, we measured the concentration of JA in the two independent idd4SRDX lines. JA was shown to coordinate immunity against necrotrophic pathogens and herbivory. We detected 10-15 fold higher levels of JA (Figure 2D) in both idd4SRDX lines indicating a function of IDD4 in the regulation of JA metabolism. The increased basal level of JA is in accordance with the up-regulation of the JA biosynthesis gene ACO2 (Figure 2E). Furthermore, the JA response genes PDF1.2, ERF1 and ORA59 (Figure 2E) are more highly expressed in idd4SRDX than WT. Interestingly, the expression of these three genes is synergistically activated by JA and ethylene (Pre et al. 2008) which might also indicate altered ethylene homeostasis in idd4SRDX.

\section{Dominant-negative IDD4 lines show enhanced resistance against Pst DC3000 and Botrytis cinerea}

To study the impact of a dominant-negative IDD4 version on plant defense, at first, idd4SRDX lines were treated with the virulent pathogen Pst DC3000 and Pst DC3000 hrcC-. The Pst hrcC- strain is impaired in virulence due to its incapacity to deliver any bacterial effector owing to a non-functional type III-secretion system. The bacterial growth for both strains was monitored after spray-infection in five-week-old plants grown under short-day conditions. $72 \mathrm{hrs}$ after plant infection, the proliferation levels of the bacteria were approximately 1.5 -orders of magnitude reduced in the idd4SRDX lines compared to WT (Figure 3A, B). The results demonstrate that the ectopic expression of idd4SRDX in stable transgenic Arabidopsis lines increases the resistance against Pst DC3000, implying a function of IDD4 and closely related-family members in basal immunity.

The increased levels of JA in idd4SRDX plants also suggested that defense responses to necrotrophic pathogens might differ from WT. Therefore, we challenged the idd4SRDX lines with the necrotrophic 
fungus Botrytis cinerea and analyzed lesion formation on the leaf surface at $30 \mathrm{hpi}$. Lesion formation around the fungal infection sites was significantly reduced in both idd4SRDX lines when compared to WT

(Figure 3C). These findings indicate that the expression of idd4SRDX also increases resistance against necrotrophs. We reason that IDD4 and closely related family members influence immunity against necrotrophs via its regulation of JA metabolism.

\section{Reduction of SA levels restores WT-like defense response in idd4SRDX}

To test whether a reduction of the elevated free SA levels could suppress the phenotype of the idd4SRDX lines, we expressed the catabolic enzyme SAGT1 in the idd4SRDX background. SAGT1 converts SA to SA2-I- $\beta$-D-glucoside (SAG) and SA-glucose-ester (SGE) that are deemed as biologically inactive storage forms of SA (Song et al. 2009). Overexpression of SAGT1 (SAGT1ox) in the idd4SRDX lines partially reconstituted the WT phenotype (Figure 3E, S2A) and restored susceptibility to Pst DC3000 hrcC- at WT levels, 72 hours after Pst hrcC- infection (Figure 3D). Furthermore, the level of reactive oxygen species $\mathrm{H}_{2} \mathrm{O}_{2}$ was significantly diminished in idd4SRDX/SAGT1ox compared to idd4SRDX after DAB staining evaluation (Figure 3E, S2B), implying a reduced SA-mediated $\mathrm{H}_{2} \mathrm{O}_{2}$ accumulation. To assure that the restored phenotype in idd4SRDX/SAGT1ox is not provoked by the silencing of the IDD4SRDX transgene, we confirmed its expression by RT-PCR (Figure S2C). Finally, to discerning whether the compromised pathogen resistance of the idd4SRDX/SAGT10x was caused by changes in the SA hormonal levels, the concentration of free SA was determined by LC-MS/MS. Unlike the idd4SRDX line, which possessed strongly increased SA levels, the amounts of free SA in the idd4SRDX/SAGT1ox line were as low as in WT (Figure 3F). These results demonstrate the biological significance of the IDD4-mediated transcriptional control of SA biosynthesis genes in plant immunity and proper plant growth. 


\section{Transcriptome reprogramming by idd4SRDX towards defense adaptation}

To identify differentially regulated genes in idd4SRDX, we performed RNA-SEQ analysis of 14 day-old independent transgenic idd4SRDX lines. To determine whether in idd4SRDX the whole transcriptome or a distinct subset of genes is affected, we calculated the Pearson correlation of differentially expressed genes. Furthermore, we determined the correlation coefficient for WT plants treated by the PAMP flg22. A close to a linear correlation coefficient of WT versus idd4SRDX (0.958), and WT versus WT (flg22) (0.927) was obtained after taking into account the expression profiles for all transcripts (FPKM) (Figure 4A-B). The strict correlation suggests that idd4SRDX does not affect general gene expression, but rather influences subsets of genes of particular biological processes. At a stringency of $p \leq 0.01,2362$ differentially regulated genes (DEGs) (Table S2) could be identified that show a $\log _{2}$-fold change from 0.4 to 5.07 of positively regulated genes and from -3.00 to -0.39 of negatively regulated genes. Among these 2362 genes, 1520 genes are up- and 842 genes are down-regulated (Figure 4C). To categorize DEGs in functional modules, we determined the gene ontology (GO) terms by using the AgriGO (Tian et al. 2017) platform. The upregulated genes can be categorized in GO terms for innate immune response, salicylic acid, and jasmonic acid metabolic process. Furthermore, the PTI-receptor components FLS2, BIR1, SOBIR1, and RPL23 are upregulated as the signaling factors MPK3, MPK11 and MAP3K16 (Table S5A) (Bigeard et al. 2015; Meng and Zhang 2013). The transcriptome composition of the up-regulated genes in idd4SRDX lines showed a high overlap of $23.6 \%$ with the genome-wide up-regulated genes of 14 day-old WT plants that were treated with flg22 for $1 \mathrm{~h}$ (2553 genes, $\mathrm{p} \leq 0.05$, Figure 4D, Table S4). Among the overlapping set of up-regulated genes (602 genes), the most significantly enriched GO categories belong to innate immune response, SA, JA- and ethylene biosynthetic process (Figure 4F, Table S3). If we align all differentially regulated genes in idd4SRDX (2362 genes) and flg22-treated WT plants (4020 genes, $\mathrm{p} \leq 0.05$ ), then an overlap of $41.3 \%$ emerged. Regarding the hypersensitive response phenotype observed in the idd4SRDX lines, the upregulated genes can be grouped into modules for oxygen and reactive oxygen species metabolic process 
and plant-type hypersensitive response (Figure 4E, Table S1). Furthermore, the up-regulated genes can be grouped in GO terms for SA-, JA- and ethylene biosynthetic process corresponding to the hormonal measurements. Taken together, this comparison illustrates the reprogramming of the transcriptome in the idd4SRDX lines towards a plant that is challenged by flg22 and suggest IDD4 as a key mediator of the immune response in Arabidopsis.

\section{Regulation of SA metabolism and signaling}

The comparison of the up-regulated genes of idd4SRDX versus WT emphasizes GO terms particularly for hormonal control and defense response (Figure 4E-F, Table S1). Notably, pivotal factors involved in SA biosynthesis and signaling are up-regulated in idd4SRDX lines (Table S5B-C). The level of the key SA biosynthesis gene ICS1 that catalyzes the conversion of chorismate to isochorismate is strikingly increased in the RNA-SEQ analysis (Table S5B, Figure 2B). Moreover, the expressions of SARD1, WRKY28 and WRKY46 (Table S5B, Figure 2B-C) that cooperatively mediate the expression of ICS1 are up-regulated in the idd4SRDX lines. The SA receptor components and NPR1-interaction factors NIMIN1/2/3 and NPR3 are also among the up-regulated genes (Table S5B) as well as PKS5, WRKY38 (Figure 2C) and the PATHOGENICITY-RELATED FACTORS PR2 and PR5 whose expression directly depends on SA-action (Seo et al. 2008) (Table S5A-B, Figure 1J). Furthermore, the PAMP-triggered SA-dependent immunity marker FRK1 is highly expressed (Table S5A, Figure 1I). All in all, the up-regulation of SA metabolic and signaling genes in the idd4SRDX lines confirms the role of IDD4 in mediating SA-dependent innate immunity.

\section{Regulation of jasmonic acid and ethylene metabolism and signaling}

In addition to up-regulated SA-biosynthesis genes, the RNA-SEQ-based transcriptome study of idd4SRDX lines revealed the elevated expression of genes that contribute to JA- and ethylene metabolism. Intriguingly, the elevated JA levels are accompanied by GO terms highlighting genes involved in JA biosynthesis process and JA -mediated signaling pathway (Figure 4E, Table S1). 
We detected stronger expression of $P R 3$ and PR4 whose expression directly depends on JA (Seo et al. 2008) and of ALLENE OXIDE CYCLASE 1 (AOC1) and AOC2 (Table S5D) which code for enzymes, whose catalyze the rate-limiting step in octadecanoid and JA-biosynthesis (Stenzel et al. 2003). Similarly, the genes of the chloroplast-located LIPOXYGENASE 1 (LOX1), LOX3, LOX4, and LOX6 are higher expressed than in WT and are required for wound-induced JA accumulation (Table S5D). Interestingly, ERF1, ORA59, and PDF1.2, whose expression is synergistically promoted by JA and ethylene, are up-regulated (Table S5D-E) thereby suggesting increased levels of ethylene in idd4SRDX (Pre et al. 2008). In this context, the conversion of S-adenosyl-L-methionine to 1-aminocyclopropane-1-carboxylate (ACC) is the first committed and generally rate-limiting step in ethylene biosynthesis and is catalyzed by the enzyme ACC synthase (ACS). We found the ACS family members ACS4, 5, 8 and 11 were up-regulated in the idd4SRDX lines. Furthermore, factors that contribute to ethylene signaling like the ETHYLENE RESPONSE SENSOR 2 (ERS2) and several further ETHYLENE-RESPONSE FACTORS show an increased expression (Table S5E). Taken together, these results show that apart of SA and JA, genes are expressed that promote ethylene biosynthesis thereby suggesting an elevated level of this biotic stress hormone in idd4RDX.

\section{Functional clusters contributing to plant growth and development are compromised in idd4SRDX plants}

To decide whether the differentially regulated genes in idd4SRDX that can be considered as major IDD4 targets, we took into account genome-wide binding studies of IDD4 of non-elicited plants (O'Malley et al. 2016). The association of IDD4 to particular chromatin regions was gained after DNA affinity purification sequencing (DAP-SEQ). In that study, the Arabidopsis cistrome was defined to unveil the binding motifs and peaks for 529 TFs. Moreover, a genome-wide overview of primary target genes was provided for these TFs (O'Malley et al. 2016). One of the analyzed TFs in this study was IDD4 that we also confirmed to be localized to the nucleus (Moreno-Risueno et al. 2015) in Arabidopsis (Figure 5A). The most frequent binding site of IDD4 was determined to carry the core-sequence A/C/GGACAA (nucleotides 8-13) (Figure 
5B), also called ID1-cis motif. Based on the analysis of the distribution of significant IDD4 binding sites (blue arrows) containing the ID1-cis motif in the proximate sequence upstream of the transcriptional start sequence (TSS), 444 repressed genes in idd4SRDX plants could be assigned as primary downstream targets (Table S6). To arrange these genes in functional clusters, we used the STRING 10 database. This web resource critically evaluates and integrates information from numerous sources, including experimental repositories, computational prediction methods and public text collections, consequently acting as a meta-database that plots all protein-protein interactions, including direct (physical) as well as indirect (functional) associations (Jensen et al. 2009; Szklarczyk et al. 2015). By using STRING 10, we identified functional groups among others for Gibberellin-signaling/-response, Stomatal-patterning/-aperture and Auxin-transport/-signaling (Figure 5I, 5N, 6E). Major IDD4 target genes such as GA INSENSITIVE DWARF1B (GID1B) (Ueguchi-Tanaka et al. 2005), SCARECROW-LIKE 3 (SCL3)(Zhang et al. 2011), GIBBERELLIN 3OXIDASE (GA3OX) 1 and HOMEOBOX GENE 1 (ATH1) (Garcia-Martinez and Gil 2001) that promote gibberellin signaling and biosynthesis are reduced in their expression (Figure 5C-I). Furthermore, GID1B expression is compromised in idd4SRDX before and after flg22-treatment and IDD4 binds to several regions upstream of the transcriptional start sequence (TSS), in which multiple ID1-cis motifs can be found. Likewise, the binding of IDD4 to the ID1-cis motif-containing sequences upstream of the TSS could be confirmed for GA3OX1, ATH1, and SCL3 (Figure 5C-F). The downregulation of these genes in idd4SRDX indicates IDD4 as a positive regulator of their expression and function. By contrast, we found genes that promote GA catabolism such as GIBBERELLIN 2-OXIDASE (GA2OX) 2, GA2OX6, GA2OX8 (Singh et al. 2002) and those that repress GA-response such as REPRESSOR OF GA-like (RGL) 1 and RGL3 (Daviere and Achard 2013) as being more highly expressed in idd4SRDX than in WT (Figure 5H). These results suggest that IDD4 functions in promoting GA-biosynthesis and -signaling.

Furthermore, we identified several genes that can be clustered to function in stomatal patterning and aperture. In this context, we identified STOMAGEN (Pillitteri et al. 2007) and SPEECHLESS (Lampard et al. 
2008) that control stomata development, as two major IDD4 binding targets in the DAP-SEQ as being down-regulated in idd4SRDX (Figure 5K-N). In addition, further genes such as STOMATAL DENSITY AND DISTRIBUTION 1 (SDD1) (Yoo et al. 2010), and MUTE, a basic helix-loop-helix (bHLH) protein that controls meristemoid differentiation during stomatal development (Pillitteri et al. 2007) are compromised in their expression in idd4SRDX. In Figure 1G, we showed that the stomatal aperture in idd4SRDX is constitutively diminished and the bacterial-triggered reopening process is impaired. In this regard, we found several differentially regulated genes that have been shown to determine stomatal aperture such as POTASSIUM CHANNEL IN ARABIDOPSIS THALIANA 2 (KAT2), that is critical for the stomatal opening induced by blue light and circadian clock (Zhang et al. 2016), EMBRYO SAC DEVELOPMENT ARREST 39 (EDA39) (Zhou et al. 2012), NITRATE TRANSPORTER 1.1 (NRT1.1) (Guo et al. 2003), the protein kinase phosphatase PP2C5 (Brock et al. 2010) and SYP121, that encodes a trafficking protein (Eisenach et al. 2012) (Figure 5M). Altogether, these findings suggest that IDD4 contributes directly to the regulation of genes that govern stomatal development. In addition, the transcriptional deregulation of genes involved in stomatal patterning, movement and responsiveness to biotic stress responses implies a genetic interaction of IDD4 with these factors.

Moreover, the plant hormone auxin is essential for coordinating plant growth and differentiation by controlling cell division/expansion/differentiation, embryogenesis, flowering and lateral root formation (Ljung 2013; Schlereth et al. 2010). idd4SRDX plants are affected in growth and immune-repression that might be caused by the deregulation of genes that coordinate auxin-transport and signaling. Indeed, we identified several genes that were shown to be directly bound by IDD4 in the DAP-SEQ study (O'Malley et al. 2016). PIN5 and PIN-LIKES 3 are down-regulated in idd4SRDX and identified as direct targets of IDD4 (Figure 6A-C). Both genes code for proteins that belong to the auxin efflux carrier family that are involved in auxin transport from the cytosol to the lumen of the endoplasmatic reticulum and mediate the intracellular auxin homeostasis (Barbez et al. 2012; Mravec et al. 2009). Furthermore, the DNA-binding 
study and idd4SRDX RNA-SEQ data suggest INDOLE-3-ACETIC ACID INDUCIBLE 24/MONOPTEROS (IAA24)

as a direct target gene of IDD4 (Figure 6A, D). The biological function of IAA24 has been intensively studied, and it was shown to be essential for embryo-axis formation, cell polarity, pattern phyllotaxis and vascular development (Bhatia et al. 2016; Schlereth et al. 2010). In addition, we identified several genes that are up-regulated in idd4SRDX and contribute to auxin-metabolism, such as WES and DFL1. Moreover, ARF19, IAA19, and PIN19 involved in auxin signaling and transport show an elevated expression (Figure 6A). The cluster analysis revealed a direct relationship between those genes and suggests IDD4 as a general up-stream regulator of these deregulated targets (Figure 6E). Our findings show that several genes that contribute to auxin biosynthesis and transport are differentially expressed thereby suggesting that the auxin-signaling system and associated developmental processes are compromised in idd4SRDX plants

\section{Immune-modulators are affected in their expression}

The auto-immune phenotype in idd4SRDX might be caused by the transcriptional repression of factors that suppress the plant defense system. Indeed, we identified factors that impact the activation of MAP kinase-signaling cascade while others compromise immunity upon target gene expression. In this context, we found the PP2C-type Phosphatase AP2C1, that dephosphorylates and consequently deactivates MPK3, 4 and 6 (Brock et al. 2010; Schweighofer et al. 2007) as being downregulated in the idd4SRDX lines with a $\log _{2}(\mathrm{FC})$ of -0.45 (Figure 5M). By qPCR, we confirmed its downregulation in idd4SRDX and could show an up-regulation in the IDD4ox lines (Figure $6 \mathrm{~F}$ ). Interestingly, as shown in Figure $\mathbf{1 H}$, the activation of MPK3 and MPK6 in idd4SRDX lines after flg22 treatment was enhanced after flg22-application when compared to WT and IDD4ox. This finding suggests that the reduced expression of $A P 2 C 1$ results in the attenuated dephosphorylation of MPK3 and MPK6 in idd4SRDX.

Furthermore, WRKY27 was reported to contribute to disease symptom development in response to the bacterial wilt pathogen Ralstonia solanacearum (Mukhtar et al. 2008). The wrky27-1 plants showed 
delayed disease symptom generation and did not show $P R$ marker gene expression. In our RNA-SEQ study, we found WRKY27 as being differentially expressed in the idd4SRDX lines (Figure 5M). Interestingly, as shown in Figure 5J, IDD4 binds to the promoter region of WRKY27 and a specific area in the gene body with an accumulation of the IDD4 binding motifs AGACAA and GGACAA thereby suggesting WRKY27 as a direct target of IDD4. The differential expression of WRKY27 might contribute to the enhanced disease symptoms and the auto-immune phenotype of idd4SRDX plants.

Stress-related deadenylation of mRNA is a control mechanism in response to biotic and abiotic stresses (Gutierrez et al. 2002). In yeast, the CCR4 associated factor 1 (CAF1) mediates deadenylation as part of the well-characterized CCR4-NOT complex (Denis and Chen 2003). The Arabidopsis homologs AtCAF1a of the yeast CAF1 gene complement the yeast caf1 mutant and exhibit deadenylation activity in vivo and a transcriptional induction by stress hormones (Liang et al. 2009; Walley et al. 2010). Furthermore, AtCAF1a mutant plants are compromised in resistance to Pst DC3000 (Liang et al. 2009). The genome-wide binding study showed IDD4-binding close to the CAF1 gene-body and implies CAF1 as a direct target (Figure $6 \mathbf{H}$ ) (O'Malley et al. 2016). Furthermore, CAF1a was differentially regulated in the idd4SRDX lines, while the expression in IDD4ox lines was indistinguishable from WT (Figure 5M, 6G) suggesting a transcriptional regulation of CAF1a by IDD4.

Taken together, we showed that genes and associated functional clusters which promote growth and development are compromised in idd4SRDX plants. However, activators of immune-response and associated phytohormone pathways are constitutively up-regulated. These data suggest that IDD4 and closely related family members are repressors of plant defense-processes including the biosynthesis of SA and JA. 


\section{Discussion}

In the present study, we showed that the expression of an IDD4-amphiphilic repressor construct in Arabidopsis activates the metabolism of SA, JA, and ethylene, in accordance with hormonal measurements and marker gene expression. These key-biotic stress hormones coordinate pivotal and distinct response pathways to cope with different sorts of pathogenic challenges.

\section{Regulation of SA-biosynthesis}

The biosynthesis of SA is induced upon challenge by various pathogens to establish systemic acquired resistance (SAR) and local resistance. A variety of genes essential for SA biosynthesis is up-regulated in idd4SRDX lines. The key biosynthesis gene ICS1 and its main upstream regulator SARD1, WRKY28 and WRKY46, as well as EDS1 and PAD4 are highly expressed. Notably, CCA1 HIKING EXPEDITION (CHE) that regulates systemic induction of ICS1 by promoting SARD1 (Zheng et al. 2015) is enriched (Table S5B). To shed light on factors that control systemic immunity and PAMP-triggered immunity, the up-regulation of SARD1 in the idd4SRDX lines could indeed play a critical role. Recently SARD1 and CBP60g were shown to be master regulators of the plant immune response that bind to the promoter region of several defense regulators that function upstream of SA biosynthesis (Sun et al. 2015). In this context, SARD1 has been demonstrated to target and exert transcriptional control of EDS1, PAD4, ADR1-L1 and ADR1_L2 factors (Table S5B) that promote SA biosynthesis during pathogen infection. Negative regulators of plant immunity whose expression depends on SARD1-mediated induction comprise NUDT6, BAP1, and WRKY4O (Table S2) (Sun et al. 2015). To balance high SA levels, S3H is up-regulated and catabolizes free SA in an inactive storage form (Zhang et al. 2013). These findings demonstrate that the core network regulating SA biosynthesis and catabolism is subject to IDD regulation. Loss of IDD function in idd4SRDX provokes the pathogen-independent activation and accumulation of SA as seen in idd4SRDX lines. 


\section{The interplay of the biotic-stress hormones}

SA acts antagonistically to JA and ethylene action and biosynthesis, which work synergistically to set up adaptation to wounding and the infection by necrotrophic pathogens. Elevated SA levels are a core element in innate immunity in response to biotrophic and hemibiotrophic phytopathogens. The SAmediated hypersensitive response is a critical instrument in the defense response to avoid spreading of the pathogen in the host tissue and establishing a long-term response to the pathogen. Surprisingly, the SA and JA levels are consistently increased in the idd4SRDX lines which concomitantly show increased resistance against PstDC3000 and Botrytis cinerea. Moreover, marker gene analysis of ERF1, ORA59, PDF1.2 indicates that the ethylene homeostasis is as well promoted. The increased levels of these three biotic stress hormones refer to IDD function as a general repressor of their hormonal biosynthesis pathways. Furthermore, elevated resistance against PstDC3000 and Botrytis cinerea suggest that the canonical antagonistic nature of SA vs JA in defense adaptation (Robert-Seilaniantz et al. 2011) to hemi/biotrophs and necrotrophs might be abrogated by the expression of idd4SRDX. Reminiscent of our findings, Lui and colleagues discovered a non-canonical pathway showing the induction of JA-responsive genes and de novo JA biosynthesis in response to SA accumulation (Liu et al. 2016) which indicates that JA contributes positively to ETI (Tsuda and Katagiri 2010). Moreover, it was reported that the JA rise is mediated by the SA receptors NPR3 and NPR4 which interact and degrade the JA signaling repressors JAZs in a SA-dependent manner. In this way, JA signaling regulates positively the early stage of RPS2-mediated ETI and enables the plant to take advantage of the hypersensitive response (HR) to fight against biotrophic pathogens without giving the plant more susceptibility against necrotrophic pathogen growth in tissues undergoing HR cell death. In this context, it was shown that the JA signaling pathway is activated in the surrounding cells adjacent to the SA accumulating cells around the infection site after avirulent Pseudomonas infection (Betsuyaku et al. 2018; Spoel et al. 2007). Recent findings suggest that the degree of synergistic interaction of SA and JA in Arabidopsis depends further on their concentrations and the sort 
of pathogenic intruder. Interestingly, the transient application of low concentrations of JA and SA provoked the expression of a wide set of common target genes, whereas SA-JA antagonism was observed at prolonged treatments and higher concentrations (Mur et al. 2006). Furthermore, JA signaling promotes resistance to the biotrophic pathogen Xanthomonas oryzae (Yamada et al. 2012) and, unlike the virulent PstDC3000 strain, the avirulent PstDC3000 strains avrRpt2 and avrRpm1 do not suppress JA-dependent defense which concurrently supports the resistance against Alternaria brassicicola (Spoel et al. 2007).

\section{IDDs and DELLAs - two sides of the same medal}

IDDs act as a DNA-scaffold protein of the transcriptional co-activators DELLAs (Fukazawa et al. 2014; Yoshida and Ueguchi-Tanaka 2014), which cannot bind directly to DNA, due to the lack of a DNA-binding domain. GA-mediated degradation of DELLA is delayed by flg22-treatment which suggests a function of IDDs to stabilize DELLAs under particular stress conditions (Navarro et al. 2008). GA stimulates cell division/expansion in response to light or darkness (photomorphogenesis and skotomorphogenesis) and regulates flower initiation and its development and is essential for male and female fertility. The DELLA quadruple loss-of-function mutant gai-t6 rga-t2 $\mathrm{rg} / 1-1 \mathrm{rg} / 2-1$ displayed a reduction to Pst DC3000 infection accompanied by an enrichment of free SA (Navarro et al. 2008). In accordance, idd4SRDX lines are also significantly less susceptible to Pst DC3000 and accumulate free SA. Together, these findings suggest that IDDs and DELLAs synergistically repress plant responses to bacterial infection and suppress SA-biosynthesis. The idd4SRDX transcriptome revealed elevated expression of the GA catabolic genes GIBBERELLIN 2-OXIDASE 2, 6 and 8 that converts the active form of GA into an inactive version and of GIBBERELLIC ACID METHYLTRANSFERASE 2 (GAMT2), a repressor of Gibberellin production (Figure $\mathbf{5 H}$ ). Additionally, RGL1 and $R G L 3$, negative regulators of GA responses, are up-regulated. On the other hand, GID1B, encoding a gibberellin (GA) receptor and also GIBBERELLIN 3-OXIDASE 1 (GA3OX1) involved in the production of bioactive GA are down-regulated and considered as direct target genes of IDD4. Likewise, $S C L 3$, a GA response factor, whose induction depends on the synergistic function of IDD4 and DELLA/RGA, 
is compromised in its expression (Figure 5H). The co-repressor SCL3 competes with DELLAs for the binding to IDD proteins that eventually results in the antagonistic regulation of GA signaling pathways (Yoshida and Ueguchi-Tanaka 2014). The deregulation of these genes in idd4SRDX, by taking into account their status as direct target genes, suggest IDD4 as an activator of GA metabolism and function. Moreover, the IDD4 family member GAI-ASSOCIATED FACTOR1/IDD2 regulates GA homeostasis and signaling in Arabidopsis by exerting transcriptional control on genes which are part of GA feedback regulation. IDD2 forms a complex with DELLA/GAI and TOPLESS RELATED and GA converts the trimeric complex from a transcriptional activator to a repressor upon the degradation of DELLA (Fukazawa et al. 2014). The IDD2/GAI complex also binds to the $5^{\prime}$-sequence of the TSS of GA3ox2, GID1b and RGL1 and exerts transcriptional control as shown in trans-activation assays. This example illustrates the redundant function of IDD members in the GA-feedback regulation. Interestingly, besides the role of DELLAs as coactivators, they can also inhibit transcriptional activation of, e.g., PIFs in the low-light response by preventing their DNA binding or with JAZ to promote JA-signaling. These two functions of DELLA working mechanisms can be considered as a key element in GA-signaling. Low GA levels suppress the expression of genes involved in growth and development by the titration of transcriptional activators (PIFs) and concomitantly promote genes dedicated to GA-feedback regulation (Fukazawa et al. 2014; Li et al. 2016). It is thus conceivable that IDD4 and other IDD family members redundantly activate GA biosynthesis after PAMP perception, to promote plant growth and to reset the plant immune system.

\section{Future perspectives}

The IDD gene family is highly conserved in the plant kingdom, and closely related members were identified in monocots and dicots. Coelho and colleagues (Coelho et al. 2018) explored the phylogenic relationships among grass IDDs for which reference genome sequences were available. In this way, IDD sequences were identified in Setaria viridis, Brachypodium distachyon, Oropetium thomaeum, Sorghum bicolor and as previously described Oryza sativa and Zea mays (Colasanti et al. 2006). The IDD sequences were identified 
by their conserved features like the $\mathrm{N}$-terminal nuclear localization signal and most importantly the four zinc finger-containing ID1 domains. The ID1 domain determines the DNA-binding to conserved cisregulatory sequences and the high degree of conservation suggests that, across the plant kingdom, IDDs control similar biological processes by exerting transcriptional control on primary target genes (Colasanti et al. 2006). Notably, IDD proteins occupy multiple functions by integrating metabolism with development and are proposed as good targets for genetic modification through either classical breeding or genome editing/ engineering technologies (Coelho et al. 2018). In this regard, recent publications describe IDD function to regulate $C_{4}$ Kranz anatomy in maize and imply them in engineering $C_{4}$ traits into $C_{3}$ crops (Coelho et al. 2018; Wang et al. 2014). The directive autoimmune phenotype and the consistently increased hormonal levels provoked by the expression of the chimeric idd4SRDX construct bear the capacity for the generation of genetically improved crop plant. By the use of an inducible system for the idd4SRDX expression, the transgene could be conditionally activated instantly after pathogen attack to induce a stronger plant defense response in engineered crops. Alternatively, we suspect that a constant, slight expression of idd4SRDX might have a sustainable, supportive influence on the plant health and immunity and future research on this potential resource is warranted. Given the unambiguous resistance phenotype in idd4SRDX lines, this chimeric construct may serve as a valuable tool for the genetic activation of a wide collection of defense-associated traits to cope with harsh biotic stress condition in agricultural farming.

\section{Materials and methods}

\section{Plant Material and Growth Conditions}

Experiments were performed by the use of Arabidopsis thaliana (Columbia accession) grown on soil in plant growth chambers (Percival Scientific) under short-day conditions ( $8 \mathrm{~h}$ light/ $16 \mathrm{~h}$ dark) and long-day condition (16h light/8h dark) at $22^{\circ} \mathrm{C}$, respectively. 


\section{Plasmid construction}

Whole seedling Arabidopsis cDNA library was used to amplify the coding sequence (CDS) of SAGT1 and IDD4 by using oligonucleotides that add the SRDX coding sequence on the 3 '-terminus of the IDD4 fragment. Subsequently, the entry clone was generated by introducing the CDS either in the $p E N T R$-vector or $p C R^{\circledR} 8 / G W / T O P O^{\circledR}$ using the pENTR $^{\mathrm{TM}}$ Directional TOPO ${ }^{\circledR}$ Cloning Kit by INVITROGEN according to manufactory's instruction. Subsequently, IDD4 and idd4SRDX were cloned into destination vectors expressing the cDNA under UBIQUITIN10 promoter (Grefen et al. 2010). SAGT1 was cloned in the $p G W B 5$ vector (Invitrogen).

\section{Overview of used oligo-nucleotides}

\begin{tabular}{|c|c|c|}
\hline Primer & Sequence & Description \\
\hline SAGT1 5' & ATGGAGCATAAGAGAGGACA & CDNA SAGT1 \\
\hline SAGT1 3' & TTTGCTCTGAACCCTTGATA & cDNA SAGT1 \\
\hline P81 & CACCATGTCGTCATCATCATATAACAC & CDNA IDD4, AT2G02080 \\
\hline P82 & TCWAACCTCTTCCAAATGGATAATTTTG & cDNA IDD4, AT2G02080 \\
\hline $352 \mathrm{~s}$ & GGTGGAGGACGAATTATGGA & CDNA IDD4, AT2G02080 \\
\hline 251as & AATCTCAACTCCAAATCCAAATCC & IDD4-SRDX \\
\hline 105as & $\begin{array}{l}\text { TCAAGCGAATCCCAATCTCAACTCCAAATCCAAATCCAAACCTCTTCCAAAT } \\
\text { GGATAA }\end{array}$ & IDD4-SRDX-STOP \\
\hline RV16s & accacctgaaaggaagtacagtg & Actin AT3G18780, genomic: 210bp cDNA: 124bp \\
\hline RV16as & ctgtgaacgattcctggacctgc & Actin AT3G18780, genomic: 210bp cDNA: 124bp \\
\hline PDF1.2a-F & AGAAGTTGTGCGAGAAGCCAAG & qPCR PDF1.2 \\
\hline PDF1.2a-R & GTGTGCTGGGAAGACATAGTTGC & qPCR PDF1.2 \\
\hline $193 \mathrm{~s}$ & AGACATCGTTGCTCTTCACG & qPCR SARD1 \\
\hline 193as & CACACTTACTTCTCCGGCAA & qPCR SARD1 \\
\hline 175s & ACGGGCATAGTTCCACAAAG & qPCR FRK1 \\
\hline 175as & CGTCAAAAGAACGACGATGA & qPCR FRK1 \\
\hline P926 & ACTAGCAAACCCAGTGGCTC & qPCR WRKY22 \\
\hline P927 & CATGCCCAGACATCGGAGTT & qPCR WRKY22 \\
\hline 196s & GACGGGTATCTTTGGAGGAA & qPCR WRKY38 \\
\hline 196as & AAACCGGAGGATTGTCTTTTG & qPCR WRKY38 \\
\hline $198 \mathrm{~s}$ & TCCAGCAGCGTATGAATCTC & qPCR WRKY28 \\
\hline 198as & GCACCACCATTGATTACGTC & qPCR WRKY28 \\
\hline
\end{tabular}




\begin{tabular}{|c|c|c|}
\hline 199s & GAGCAATCGGAAGACATGAA & qPCR WRKY46 \\
\hline 199as & TTCCACACACCGTTCTCAAT & qPCR WRKY46 \\
\hline $87 s$ & GAATCGGTCGTTTGGTTGCTA & qPCR GADPH \\
\hline 87as & TTAACAGCGACGAGCTCAACAT & qPCR GADPH \\
\hline ksk-145 & TATGGGGGATAAGGGGTTCT & qPCR ICS1 \\
\hline ksk-146 & GCCCTAGTTACAACCCGAAA & qPCR ICS1 \\
\hline ksk-155 & ATCGTTGGAAATCGTGGTGT & qPCR PR2 \\
\hline ksk-156 & TCGGTGATCCATTCTTCACA & qPCR PR2 \\
\hline ksk-170 & TCCCAACACTTTCATCGTCA & qPCR DLO1/S3H \\
\hline ksk-171 & ACGGCTCTATGGAGCACACT & qPCR DLO1/S3H \\
\hline ksk-123 & GTACCGCCGTCTAAGGACAT & qPCR AOC2 \\
\hline ksk-124 & CACAGCGATACGAGAAACATT & qPCR AOC2 \\
\hline $167 s$ & GAGGATGGTTGTTCTCCGGT & qPCR ERF1 \\
\hline 167as & AGACCCCAAAAGCTCCTCAA & qPCR ERF1 \\
\hline P808 & ATTCGCGGCCGAGATAAGAG & qPCR ORA59 \\
\hline P809 & GGCTGCCTTTCAAAGCGAAA & qPCR ORA59 \\
\hline 267s & CGCTCCTGGTCCATTATCTT & qPCR AP2C1 \\
\hline 267as & CAAATCCAGCAACACCAATC & qPCR AP2C1 \\
\hline $361 \mathrm{~s}$ & ATGCGTTTCAGAGGATGAGG & qPCR CAF1a \\
\hline 361as & CAAAACCCCAGCATGTTTCT & qPCR CAF1a \\
\hline $335 s$ & TTGCGGTGTTGTTGTTGTCT & qPCR GID1B \\
\hline 335as & GTTGAGAGCGTTCCATCCAT & qPCR GID1B \\
\hline
\end{tabular}

\section{RNA Extraction and real-time quantitative PCR analysis}

Total RNAs were extracted from 14 day-old seedlings, grown on half-strength Murashige and Skoog (MS) plates, with the NucleoSpin ${ }^{\circledR}$ RNA Plant (MACHEREY-NAGEL), according to the manufacturer's instructions. First strand cDNA was synthesised from $5 \mu \mathrm{g}$ of total RNAs using SuperScript ${ }^{\circledR}$ First-Strand Synthesis System for RT-PCR (Lifetechnology) according to the manufacturer's instructions. The cDNA stock was diluted to a final concentration of $25 \mathrm{ng} / \mathrm{ul}$. Subsequently, $500 \mathrm{nM}$ of each primer was applied and mixed with LightCycler ${ }^{\circledast} 480$ Sybr Green I Master mix (Roche Applied Science) for quantitative PCR analysis, according to the manufacturer's instructions. Products were amplified and fluorescent signals acquired with a LightCycler $^{\circledR} 480$ detection system. The specificity of amplification products was determined by melting curves. GADPH was used as internal control for signals normalization. Exor4 
relative quantification software (Roche Applied Science) automatically calculates the relative expression level of the selected genes with algorithms based on the $\Delta \Delta \mathrm{Ct}$ method. Data generated from duplicates of at least three biological replicates (bioRep) were used.

\section{Bioinformatics analysis of RNA-SEQ data}

Sequencing was performed on each library to generate 101-bp paired-end reads on the Illumina HiSeq2500 Genome Analyzer platform. Read quality was checked using FastQC and low-quality reads were trimmed using the Trimmomatic version 0.32 (http://www.usadellab.org/cms/?page=trimmomatic) with the following parameters: Minimum length of $36 \mathrm{bp}$; Mean Phred quality score higher than 30; Leading and trailing bases removal with base quality below 3; Sliding window of 4:15. After pre-processing the Illumina reads, the transcript structures were reconstructed using a series of programs, namely, TopHat (ver. 2.1.1; http://tophat.cbcb.umd.edu/) for aligning with the genome, and Cufflinks (ver. 2.2.1; http://cufflinks.cbcb.umd.edu/) for gene structure predictions. For TopHat, the Reference-Arabidopsis thaliana (TAIR10) genome (https://www.arabidopsis.org) was used as the reference sequences with a maximum number of mismatches as 2 . To identify the differentially expressed genes, the following parameters were used: $p$-value of 0.05 with a statistical correction using Benjamini Hochberg FDR of 0.05 in cuffdiff. A cut-off of 2 fold up- or down-regulation has been chosen to define the differential expression. After processing the data, visualization of differential expression was done using cummeRbund v2.14.0 (http://bioconductor.org/packages/release/bioc/html/cummeRbund.html). Differentially regulated genes that are common among the samples were identified using Venny. The complete RNA-SEQ data is available at the GEO repository (GEO accession GSE120791).

\section{GO term analysis}


For the GO term analysis, AGRIGO analysis tool was used (http://bioinfo.cau.edu.cn/agriGO/, (Tian et al. 2017) by using significantly differentially expressed genes between the tested conditions ( $p$-value $\leq 0.05$ for WT and $\mathrm{P}$ value $\leq 0.01$ for idd4SRDX)

\section{Quantification of SA and JA}

Plant materials were lyophilized and ground in a bead beater (Biospec Products, Bartlesville, Okla., USA). Aliquots (about $5 \mathrm{mg}$ dry weight) of powdered tissues were extracted with $400 \mu \mathrm{L}$ of $10 \%$ methanol containing $1 \%$ acetic acid and internal standards (11.1 ng of ${ }^{2} \mathrm{H}_{4}-\mathrm{SA}$ and $0.25 \mathrm{ng}$ of ${ }^{2} \mathrm{H}_{2}-\mathrm{JA}$, purchased from OlchemIm Ltd., Olomouc, Czech Republic). The samples were extracted in the bead beater for $1 \mathrm{~min}$, placed in ice for $30 \mathrm{~min}$, and then centrifuged at $13,000 \mathrm{~g}$ for $10 \mathrm{~min}$ at $4{ }^{\circ} \mathrm{C}$ (Eppendorf centrifuge 5424 , Hamburg, Germany). The supernatant was carefully removed and the pellet re-extracted with $400 \mu \mathrm{L}$ of $10 \%$ methanol containing $1 \%$ acetic acid. Following further 30 min incubation in ice, the extracts were centrifuged and the supernatants combined. The samples were filtered through $0.22 \mu \mathrm{m}$ PTFE filters before LC-MS/MS analysis. Analysis of SA and JA was performed by comparing retention times, and mass transitions with the standards using an Agilent 1200 HPLC (Agilent Technologies, Waldbronn, Germany) coupled to a Q-TRAP 5500 MS (AB SCIEX, MA, USA) with an electrospray source. Chromatographic separation was carried out at $35^{\circ} \mathrm{C}$ on a Phenomenex (Torrance, CA, USA) Gemini C18 $(150 \times 2.0 \mathrm{~mm}, 5$ $\mu \mathrm{m})$ column with the solvent system formic acid/acetonitrile/water $(0.1 / 94.9 / 5, \mathrm{v} / \mathrm{v} / \mathrm{v}$; mobile phase A) and formic acid/ acetonitrile/water (0.1/5/94.9, v/v/v; mobile phase B). The gradient used was 0-20 min, 0\%-100\% A; $20-25 \mathrm{~min}, 100 \% \mathrm{~A} ; 25-26 \mathrm{~min}, 100 \%-0 \%$ A; $26-36 \mathrm{~min}, 0 \% \mathrm{~A}$. To reduce contamination of the MS, the first 5 min of the run was directed to waste using the inbuilt Valco valve. Analysis of SA and JA was based on appropriate Multiple Reaction Monitoring (MRM) of ion pairs for labeled and endogenous SA and JA using the following mass transitions: ${ }^{2} \mathrm{H}_{4} \mathrm{SA} 141>97, \mathrm{SA} 137>93 ;{ }^{2} \mathrm{H}_{2} \mathrm{JA} 211>61, \mathrm{JA} 209>59$. The MS was operated in negative ionization mode. The conditions were as follows: Temperature $500^{\circ} \mathrm{C}$, Ion source gas 150 psi, lon source gas 260 psi, lon Spray Voltage -4500 V, curtain gas 40 psi, Collision Gas 
Medium; DP (-25 V), EP (-9) and CXP (-2) were the same for all compounds. DT (50) for ${ }^{2} \mathrm{H}_{4} \mathrm{SA}$ and SA; CE (-25), and DT (100) for ${ }^{2} \mathrm{H}_{2} \mathrm{JA}$ and JA. Data of 3 bioReps (consisting of 3 technical replicates per bioRep) were acquired and analyzed using Analyst 1.4 software (Applied Biosystems).

\section{Quantitation of immunoblot membranes}

Bradford assays were used to quantify protein levels in extracts and ensure equal loading of total proteins for gels used for immunoblot analysis and EMSA.

\section{Immunoblot}

Nuclear proteins were extracted from 14 day-old seedlings grown on half MS-medium. After quantification with the Bradford method, equal amounts of proteins were resolved by SDS-PAGE and then transferred to a polyvinylidene difluoride membrane (Bio-Rad) using a Mini-Protean 3 Cell (Bio-Rad). Immunoblot analysis was performed using $1 \mu \mathrm{g} / \mathrm{mL}$ primary polyclonal $\mathrm{pTpY}$ antibodies and then with secondary antibodies conjugated to alkaline phosphatase. Antibody complexes were detected by chemiluminescence using the Immun-Start AP Substrate kit (Bio-Rad). Three bioReps were performed and shown is a representative result.

\section{Pseudomonas syringae and Botrytis cinerea infections}

Plants were spray-inoculated with Pseudomonas syringae DC3000 and Pseudomonas syringae DC3000 hrcC- at $\mathrm{OD}_{600}=0.2$ and sampled $2 \mathrm{~h}$ and $72 \mathrm{~h}$ after inoculation to determine the level of colonization as described previously (Jelenska et al. 2010). The density of colony-forming units (CFU) was analyzed 2 and 72 hours post inoculation (hpi). In three bioReps, a total of 30 plants was sampled for each plant genotype by each taking three leaf discs per plant. The Botrytis cinerea inoculum was freshly prepared for each experiment from a spore stock stored at $-80^{\circ} \mathrm{C}$ in $25 \%$ glycerol. Spores were evenly spread on PDA medium ( $200 \mathrm{~g}$ peeled potato slice, $17 \mathrm{~g}$ agar, $20 \mathrm{~g}$ dextrose, $1 \mathrm{~L}$ distilled water) and incubated at $24^{\circ} \mathrm{C}$ for 14 days. Afterward, spores were harvested and their concentration determined by the use of a 
hemocytometer. Leaves were inoculated with a $2 \mu \mathrm{l}$ droplet of a spore suspension $\left(5 \times 10^{6} \mathrm{spores} / \mathrm{ml}\right)$ and analyzed $30 \mathrm{hpi}$. In three bioReps, a total of at least 30 plants was sampled for each plant genotype.

\section{Tryphan blue staining and DAB staining}

Stainings were conducted by using 14 day-old seedlings grown under sterile conditions on half MS medium, in accordance with (Genot et al. 2017). Experiments were repeated three times with similar results and shown is a representative result.

\section{Callose deposition assay}

Leaves of 10 day-old seedlings grown under sterile conditions on half MS medium were incubated in acetic acid: ethanol $(1: 3 \mathrm{v} / \mathrm{v})$ for $8 \mathrm{~h}$ to remove the chlorophyll and subsequently rehydrated by a series of ethanol dilutions (from $70 \%-0 \% \mathrm{v} / \mathrm{v}$ ). Leaves were incubated in the dark in $0.01 \%$ aniline blue in $150 \mathrm{mM}$ $\mathrm{K}_{2} \mathrm{HPO}_{4}(\mathrm{pH} 9.5)$ and subsequently analyzed by epifluorescence microscopy. Experiments were repeated three times with similar results.

\section{ROS burst assay}

ROS burst assay was performed as described by (Smith and Heese 2014). Data of 3 bioReps (consisting of 16 technical replicates per bioRep) were acquired, and the average value is presented.

\section{Stomatal Aperture assay}

The stomatal assay was performed as described by (Zheng et al. 2015) of 3 week-old plants and subsequently analyzed by microscopy to determine the stomatal opening by calculating the area of the enclosed ellipse $a=\pi * r 1 * r 2$. Presented are the results of three bioReps.

\section{Author Contribution}


R.V., S.K., H.H designed/ performed and analyzed most of the experiments. K.M. conducted RNA-SEQ data processing. J. M. and S.A.B carried out the hormonal measurements. A.S analyzed data and performed microscopy. R.V. wrote the manuscript. H.H, S.K helped to prepare the manuscript.

\section{Supplementary data}

Supplemental information is online available and includes two figures and six tables. The complete RNASEQ data is available at the GEO repository (GEO accession GSE120791).

\section{Acknowledgments}

Funding for the project was provided to $\mathrm{HH}$ by baseline funding project BAS/1/1062 of the King Abdullah University of Science and Technology. 


\section{References:}

Abulfaraj AA, Mariappan K, Bigeard J, Manickam P, Blilou I, Guo X, Al-Babili S, Pflieger D, Hirt H, Rayapuram N (2018) The Arabidopsis homolog of human G3BP1 is a key regulator of stomatal and apoplastic immunity. Life Sci Alliance 1: e201800046

Asai T, Tena G, Plotnikova J, Willmann MR, Chiu WL, Gomez-Gomez L, Boller T, Ausubel FM, Sheen J (2002) MAP kinase signalling cascade in Arabidopsis innate immunity. Nature 415: 977-983

Barbez E, Kubes M, Rolcik J, Beziat C, Pencik A, Wang B, Rosquete MR, Zhu J, Dobrev PI, Lee Y, Zazimalova E, Petrasek J, Geisler M, Friml J, Kleine-Vehn J (2012) A novel putative auxin carrier family regulates intracellular auxin homeostasis in plants. Nature 485: 119-122

Bartsch M, Bednarek P, Vivancos PD, Schneider B, von Roepenack-Lahaye E, Foyer CH, Kombrink E, Scheel D, Parker JE (2010) Accumulation of isochorismate-derived 2,3-dihydroxybenzoic 3-O-beta-D-xyloside in arabidopsis resistance to pathogens and ageing of leaves. J Biol Chem 285: 25654-25665

Betsuyaku S, Katou S, Takebayashi Y, Sakakibara H, Nomura N, Fukuda H (2018) Salicylic Acid and Jasmonic Acid Pathways are Activated in Spatially Different Domains Around the Infection Site During EffectorTriggered Immunity in Arabidopsis thaliana. Plant \& cell physiology 59: 439

Bhatia N, Bozorg B, Larsson A, Ohno C, Jonsson H, Heisler MG (2016) Auxin Acts through MONOPTEROS to Regulate Plant Cell Polarity and Pattern Phyllotaxis. Curr Biol 26: 3202-3208

Bigeard J, Colcombet J, Hirt H (2015) Signaling mechanisms in pattern-triggered immunity (PTI). Mol Plant 8: 521-539

Brock AK, Willmann R, Kolb D, Grefen L, Lajunen HM, Bethke G, Lee J, Nurnberger T, Gust AA (2010) The Arabidopsis mitogen-activated protein kinase phosphatase PP2C5 affects seed germination, stomatal aperture, and abscisic acid-inducible gene expression. Plant Physiol 153: 1098-1111

Canet JV, Dobon A, Roig A, Tornero P (2010) Structure-function analysis of npr1 alleles in Arabidopsis reveals a role for its paralogs in the perception of salicylic acid. Plant, cell \& environment 33: 1911-1922 Cao H, Bowling SA, Gordon AS, Dong X (1994) Characterization of an Arabidopsis Mutant That Is Nonresponsive to Inducers of Systemic Acquired Resistance. The Plant cell 6: 1583-1592

Cao H, Glazebrook J, Clarke JD, Volko S, Dong X (1997) The Arabidopsis NPR1 gene that controls systemic acquired resistance encodes a novel protein containing ankyrin repeats. Cell 88: 57-63

Chen Z, Silva H, Klessig DF (1993) Active oxygen species in the induction of plant systemic acquired resistance by salicylic acid. Science 262: 1883-1886

Cheng H, Qin L, Lee S, Fu X, Richards DE, Cao D, Luo D, Harberd NP, Peng J (2004) Gibberellin regulates Arabidopsis floral development via suppression of DELLA protein function. Development 131: 1055-1064 Chini A, Fonseca S, Fernandez G, Adie B, Chico JM, Lorenzo O, Garcia-Casado G, Lopez-Vidriero I, Lozano FM, Ponce MR, Micol JL, Solano R (2007) The JAZ family of repressors is the missing link in jasmonate signalling. Nature 448: 666-671

Choi H, Oh E (2016) PIF4 Integrates Multiple Environmental and Hormonal Signals for Plant Growth Regulation in Arabidopsis. Mol Cells 39: 587-593

Coelho CP, Huang P, Lee DY, Brutnell TP (2018) Making Roots, Shoots, and Seeds: IDD Gene Family Diversification in Plants. Trends Plant Sci 23: 66-78

Colasanti J, Tremblay R, Wong AY, Coneva V, Kozaki A, Mable BK (2006) The maize INDETERMINATE1 flowering time regulator defines a highly conserved zinc finger protein family in higher plants. BMC Genomics 7: 158

Coneva V, Zhu T, Colasanti J (2007) Expression differences between normal and indeterminate1 maize suggest downstream targets of ID1, a floral transition regulator in maize. J Exp Bot 58: 3679-3693 
Cui D, Zhao J, Jing Y, Fan M, Liu J, Wang Z, Xin W, Hu Y (2013) The arabidopsis IDD14, IDD15, and IDD16 cooperatively regulate lateral organ morphogenesis and gravitropism by promoting auxin biosynthesis and transport. PLoS Genet 9: e1003759

Daviere JM, Achard P (2013) Gibberellin signaling in plants. Development 140: 1147-1151

Dempsey DA, Klessig DF (1994) Salicylic acid, active oxygen species and systemic acquired resistance in plants. Trends Cell Biol 4: 334-338

Denis CL, Chen J (2003) The CCR4-NOT complex plays diverse roles in mRNA metabolism. Prog Nucleic Acid Res Mol Biol 73: 221-250

Despres C, DeLong C, Glaze S, Liu E, Fobert PR (2000) The Arabidopsis NPR1/NIM1 protein enhances the DNA binding activity of a subgroup of the TGA family of bZIP transcription factors. Plant Cell 12: 279-290 Dill A, Jung HS, Sun TP (2001) The DELLA motif is essential for gibberellin-induced degradation of RGA. Proceedings of the National Academy of Sciences of the United States of America 98: 14162-14167 Ding Y, Sun T, Ao K, Peng Y, Zhang Y, Li X, Zhang Y (2018) Opposite Roles of Salicylic Acid Receptors NPR1 and NPR3/NPR4 in Transcriptional Regulation of Plant Immunity. Cell 173: 1454-1467 e1415 Durrant WE, Dong X (2004) Systemic acquired resistance. Annu Rev Phytopathol 42: 185-209

Eisenach C, Chen ZH, Grefen C, Blatt MR (2012) The trafficking protein SYP121 of Arabidopsis connects programmed stomatal closure and $\mathrm{K}(+)$ channel activity with vegetative growth. Plant J 69: 241-251 Fernandez-Calvo P, Chini A, Fernandez-Barbero G, Chico JM, Gimenez-Ibanez S, Geerinck J, Eeckhout D, Schweizer F, Godoy M, Franco-Zorrilla JM, Pauwels L, Witters E, Puga MI, Paz-Ares J, Goossens A, Reymond P, De Jaeger G, Solano R (2011) The Arabidopsis bHLH transcription factors MYC3 and MYC4 are targets of JAZ repressors and act additively with MYC2 in the activation of jasmonate responses. The Plant cell 23: 701-715

Feurtado JA, Huang D, Wicki-Stordeur L, Hemstock LE, Potentier MS, Tsang EW, Cutler AJ (2011) The Arabidopsis $\mathrm{C} 2 \mathrm{H} 2$ zinc finger INDETERMINATE DOMAIN1/ENHYDROUS promotes the transition to germination by regulating light and hormonal signaling during seed maturation. Plant Cell 23: 1772-1794 Franklin KA, Lee SH, Patel D, Kumar SV, Spartz AK, Gu C, Ye S, Yu P, Breen G, Cohen JD, Wigge PA, Gray WM (2011) Phytochrome-interacting factor 4 (PIF4) regulates auxin biosynthesis at high temperature. Proceedings of the National Academy of Sciences of the United States of America 108: 20231-20235

Frei dit Frey N, Garcia AV, Bigeard J, Zaag R, Bueso E, Garmier M, Pateyron S, de Tauzia-Moreau ML, Brunaud V, Balzergue S, Colcombet J, Aubourg S, Martin-Magniette ML, Hirt H (2014) Functional analysis of Arabidopsis immune-related MAPKs uncovers a role for MPK3 as negative regulator of inducible defences. Genome Biol 15: R87

Fu ZQ, Yan S, Saleh A, Wang W, Ruble J, Oka N, Mohan R, Spoel SH, Tada Y, Zheng N, Dong X (2012) NPR3 and NPR4 are receptors for the immune signal salicylic acid in plants. Nature 486: 228-232

Fukazawa J, Teramura H, Murakoshi S, Nasuno K, Nishida N, Ito T, Yoshida M, Kamiya Y, Yamaguchi S, Takahashi $Y$ (2014) DELLAs function as coactivators of GAI-ASSOCIATED FACTOR1 in regulation of gibberellin homeostasis and signaling in Arabidopsis. Plant Cell 26: 2920-2938

Gaffney T, Friedrich L, Vernooij B, Negrotto D, Nye G, Uknes S, Ward E, Kessmann H, Ryals J (1993) Requirement of salicylic Acid for the induction of systemic acquired resistance. Science 261: 754-756 Galletti R, Ferrari S, De Lorenzo G (2011) Arabidopsis MPK3 and MPK6 play different roles in basal and oligogalacturonide- or flagellin-induced resistance against Botrytis cinerea. Plant Physiol 157: 804-814

Gangappa SN, Berriri S, Kumar SV (2017) PIF4 Coordinates Thermosensory Growth and Immunity in Arabidopsis. Curr Biol 27: 243-249

Garcia-Martinez JL, Gil J (2001) Light Regulation of Gibberellin Biosynthesis and Mode of Action. J Plant Growth Regul 20: 354-368

Genot B, Lang J, Berriri S, Garmier M, Gilard F, Pateyron S, Haustraete K, Van Der Straeten D, Hirt H, Colcombet J (2017) Constitutively active Arabidopsis MAP Kinase 3 triggers defense responses involving salicylic acid and SUMM2 resistance protein. Plant Physiol 
Grefen C, Donald N, Hashimoto K, Kudla J, Schumacher K, Blatt MR (2010) A ubiquitin-10 promoter-based vector set for fluorescent protein tagging facilitates temporal stability and native protein distribution in transient and stable expression studies. Plant J 64: 355-365

Guo FQ, Young J, Crawford NM (2003) The nitrate transporter AtNRT1.1 (CHL1) functions in stomatal opening and contributes to drought susceptibility in Arabidopsis. Plant Cell 15: 107-117

Gutierrez RA, Ewing RM, Cherry JM, Green PJ (2002) Identification of unstable transcripts in Arabidopsis by cDNA microarray analysis: rapid decay is associated with a group of touch- and specific clock-controlled genes. Proceedings of the National Academy of Sciences of the United States of America 99: 11513-11518 Hermann M, Maier F, Masroor A, Hirth S, Pfitzner AJ, Pfitzner UM (2013) The Arabidopsis NIMIN proteins affect NPR1 differentially. Front Plant Sci 4: 88

Hirano Y, Nakagawa M, Suyama T, Murase K, Shirakawa M, Takayama S, Sun TP, Hakoshima T (2017) Structure of the SHR-SCR heterodimer bound to the BIRD/IDD transcriptional factor JKD. Nat Plants 3: 17010

Hiratsu K, Matsui K, Koyama T, Ohme-Takagi M (2003) Dominant repression of target genes by chimeric repressors that include the EAR motif, a repression domain, in Arabidopsis. Plant J 34: 733-739

Hiratsu K, Mitsuda N, Matsui K, Ohme-Takagi M (2004) Identification of the minimal repression domain of SUPERMAN shows that the DLELRL hexapeptide is both necessary and sufficient for repression of transcription in Arabidopsis. Biochem Biophys Res Commun 321: 172-178

Huot B, Yao J, Montgomery BL, He SY (2014) Growth-defense tradeoffs in plants: a balancing act to optimize fitness. Mol Plant 7: 1267-1287

Jelenska J, van Hal JA, Greenberg JT (2010) Pseudomonas syringae hijacks plant stress chaperone machinery for virulence. Proc Natl Acad Sci U S A 107: 13177-13182

Jensen L, Kuhn M, Stark M, Chaffron S, Creevey C, Muller J, Doerks T, Julien P, Roth A, Simonovic M, Bork $P$, von Mering $C$ (2009) STRING 8--a global view on proteins and their functional interactions in 630 organisms. Nucleic acids research 37: D412-416

Jeong EY, Seo PJ, Woo JC, Park CM (2015) AKIN10 delays flowering by inactivating IDD8 transcription factor through protein phosphorylation in Arabidopsis. BMC Plant Biol 15: 110

Jones JD, Dangl JL (2006) The plant immune system. Nature 444: 323-329

Kaisho T, Akira S (2006) Toll-like receptor function and signaling. J Allergy Clin Immunol 117: 979-987; quiz 988

Kuai X, MacLeod BJ, Despres C (2015) Integrating data on the Arabidopsis NPR1/NPR3/NPR4 salicylic acid receptors; a differentiating argument. Front Plant Sci 6: 235

Lampard GR, Macalister CA, Bergmann DC (2008) Arabidopsis stomatal initiation is controlled by MAPKmediated regulation of the bHLH SPEECHLESS. Science 322: 1113-1116

Leivar P, Monte E (2014) PIFs: systems integrators in plant development. Plant Cell 26: 56-78

Li K, Yu R, Fan LM, Wei N, Chen H, Deng XW (2016) DELLA-mediated PIF degradation contributes to coordination of light and gibberellin signalling in Arabidopsis. Nature communications 7: 11868

Li M, Chen H, Chen J, Chang M, Palmer IA, Gassmann W, Liu F, Fu ZQ (2018) TCP Transcription Factors Interact With NPR1 and Contribute Redundantly to Systemic Acquired Resistance. Frontiers in plant science 9: 1153

Li N, Han X, Feng D, Yuan D, Huang LJ (2019) Signaling Crosstalk between Salicylic Acid and Ethylene/Jasmonate in Plant Defense: Do We Understand What They Are Whispering? International journal of molecular sciences 20

Liang W, Li C, Liu F, Jiang H, Li S, Sun J, Wu X, Li C (2009) The Arabidopsis homologs of CCR4-associated factor 1 show mRNA deadenylation activity and play a role in plant defence responses. Cell Res 19: 307316 
Liu L, Sonbol FM, Huot B, Gu Y, Withers J, Mwimba M, Yao J, He SY, Dong X (2016) Salicylic acid receptors activate jasmonic acid signalling through a non-canonical pathway to promote effector-triggered immunity. Nature communications 7: 13099

Ljung K (2013) Auxin metabolism and homeostasis during plant development. Development 140: 943-950 Long Y, Smet W, Cruz-Ramirez A, Castelijns B, de Jonge W, Mahonen AP, Bouchet BP, Perez GS, Akhmanova A, Scheres B, Blilou I (2015) Arabidopsis BIRD Zinc Finger Proteins Jointly Stabilize Tissue Boundaries by Confining the Cell Fate Regulator SHORT-ROOT and Contributing to Fate Specification. Plant Cell 27: 1185-1199

Mahfouz MM, Li L, Piatek M, Fang X, Mansour H, Bangarusamy DK, Zhu JK (2012) Targeted transcriptional repression using a chimeric TALE-SRDX repressor protein. Plant Mol Biol 78: 311-321

Manohar M, Tian M, Moreau M, Park SW, Choi HW, Fei Z, Friso G, Asif M, Manosalva P, von Dahl CC, Shi K, Ma S, Dinesh-Kumar SP, O'Doherty I, Schroeder FC, van Wijk KJ, Klessig DF (2014) Identification of multiple salicylic acid-binding proteins using two high throughput screens. Frontiers in plant science 5: 777

Mao G, Meng X, Liu Y, Zheng Z, Chen Z, Zhang S (2011) Phosphorylation of a WRKY transcription factor by two pathogen-responsive MAPKs drives phytoalexin biosynthesis in Arabidopsis. Plant Cell 23: 1639-1653 Marin-de la Rosa N, Pfeiffer A, Hill K, Locascio A, Bhalerao RP, Miskolczi P, Gronlund AL, Wanchoo-Kohli A, Thomas SG, Bennett MJ, Lohmann JU, Blazquez MA, Alabadi D (2015) Genome Wide Binding Site Analysis Reveals Transcriptional Coactivation of Cytokinin-Responsive Genes by DELLA Proteins. PLoS Genet 11: e1005337

Matsubara K, Yamanouchi U, Wang ZX, Minobe Y, Izawa T, Yano M (2008) Ehd2, a rice ortholog of the maize INDETERMINATE1 gene, promotes flowering by up-regulating Ehd1. Plant Physiol 148: 1425-1435

Melotto M, Mecey C, Niu Y, Chung HS, Katsir L, Yao J, Zeng W, Thines B, Staswick P, Browse J, Howe GA, He SY (2008) A critical role of two positively charged amino acids in the Jas motif of Arabidopsis JAZ proteins in mediating coronatine- and jasmonoyl isoleucine-dependent interactions with the COI1 F-box protein. The Plant journal : for cell and molecular biology 55: 979-988

Melotto M, Underwood W, Koczan J, Nomura K, He SY (2006) Plant stomata function in innate immunity against bacterial invasion. Cell 126: 969-980

Meng X, Zhang S (2013) MAPK cascades in plant disease resistance signaling. Annu Rev Phytopathol 51: 245-266

Mitsuda N, Ohme-Takagi M (2009) Functional analysis of transcription factors in Arabidopsis. Plant Cell Physiol 50: 1232-1248

Montillet JL, Hirt H (2013) New checkpoints in stomatal defense. Trends Plant Sci 18: 295-297

Moreno-Risueno MA, Sozzani R, Yardimci GG, Petricka JJ, Vernoux T, Blilou I, Alonso J, Winter CM, Ohler U, Scheres B, Benfey PN (2015) Transcriptional control of tissue formation throughout root development. Science 350: 426-430

Mravec J, Skupa P, Bailly A, Hoyerova K, Krecek P, Bielach A, Petrasek J, Zhang J, Gaykova V, Stierhof YD, Dobrev PI, Schwarzerova K, Rolcik J, Seifertova D, Luschnig C, Benkova E, Zazimalova E, Geisler M, Friml J (2009) Subcellular homeostasis of phytohormone auxin is mediated by the ER-localized PIN5 transporter. Nature 459: 1136-1140

Mukhtar MS, Deslandes L, Auriac MC, Marco Y, Somssich IE (2008) The Arabidopsis transcription factor WRKY27 influences wilt disease symptom development caused by Ralstonia solanacearum. Plant J 56: 935-947

Mur LA, Kenton P, Atzorn R, Miersch O, Wasternack C (2006) The outcomes of concentration-specific interactions between salicylate and jasmonate signaling include synergy, antagonism, and oxidative stress leading to cell death. Plant physiology 140: 249-262

Murase K, Hirano Y, Sun TP, Hakoshima T (2008) Gibberellin-induced DELLA recognition by the gibberellin receptor GID1. Nature 456: 459-463 
Mushegian A, Medzhitov R (2001) Evolutionary perspective on innate immune recognition. J Cell Biol 155: 705-710

Navarro L, Bari R, Achard P, Lison P, Nemri A, Harberd NP, Jones JD (2008) DELLAs control plant immune responses by modulating the balance of jasmonic acid and salicylic acid signaling. Curr Biol 18: 650-655

Niu Y, Figueroa P, Browse J (2011) Characterization of JAZ-interacting bHLH transcription factors that regulate jasmonate responses in Arabidopsis. Journal of experimental botany 62: 2143-2154

O'Malley RC, Huang SC, Song L, Lewsey MG, Bartlett A, Nery JR, Galli M, Gallavotti A, Ecker JR (2016) Cistrome and Epicistrome Features Shape the Regulatory DNA Landscape. Cell 165: 1280-1292

Oh E, Zhu JY, Ryu H, Hwang I, Wang ZY (2014) TOPLESS mediates brassinosteroid-induced transcriptional repression through interaction with BZR1. Nat Commun 5: 4140

Oh E, Zhu JY, Wang ZY (2012) Interaction between BZR1 and PIF4 integrates brassinosteroid and environmental responses. Nat Cell Biol 14: 802-809

Petersen M, Brodersen P, Naested H, Andreasson E, Lindhart U, Johansen B, Nielsen HB, Lacy M, Austin MJ, Parker JE, Sharma SB, Klessig DF, Martienssen R, Mattsson O, Jensen AB, Mundy J (2000) Arabidopsis map kinase 4 negatively regulates systemic acquired resistance. Cell 103: 1111-1120

Pillitteri LJ, Sloan DB, Bogenschutz NL, Torii KU (2007) Termination of asymmetric cell division and differentiation of stomata. Nature 445: 501-505

Pre M, Atallah M, Champion A, De Vos M, Pieterse CM, Memelink J (2008) The AP2/ERF domain transcription factor ORA59 integrates jasmonic acid and ethylene signals in plant defense. Plant Physiol 147: $1347-1357$

Robert-Seilaniantz A, Grant M, Jones JD (2011) Hormone crosstalk in plant disease and defense: more than just jasmonate-salicylate antagonism. Annu Rev Phytopathol 49: 317-343

Sakuraba Y, Jeong J, Kang MY, Kim J, Paek NC, Choi G (2014) Phytochrome-interacting transcription factors PIF4 and PIF5 induce leaf senescence in Arabidopsis. Nature communications 5: 4636

Schlereth A, Moller B, Liu W, Kientz M, Flipse J, Rademacher EH, Schmid M, Jurgens G, Weijers D (2010) MONOPTEROS controls embryonic root initiation by regulating a mobile transcription factor. Nature 464 : 913-916

Schweighofer A, Kazanaviciute V, Scheikl E, Teige M, Doczi R, Hirt H, Schwanninger M, Kant M, Schuurink R, Mauch F, Buchala A, Cardinale F, Meskiene I (2007) The PP2C-type phosphatase AP2C1, which negatively regulates MPK4 and MPK6, modulates innate immunity, jasmonic acid, and ethylene levels in Arabidopsis. Plant Cell 19: 2213-2224

Seo PJ, Kim MJ, Ryu JY, Jeong EY, Park CM (2011a) Two splice variants of the IDD14 transcription factor competitively form nonfunctional heterodimers which may regulate starch metabolism. Nat Commun 2: 303

Seo PJ, Lee AK, Xiang F, Park CM (2008) Molecular and functional profiling of Arabidopsis pathogenesisrelated genes: insights into their roles in salt response of seed germination. Plant \& cell physiology 49 : 334-344

Seo PJ, Ryu J, Kang SK, Park CM (2011b) Modulation of sugar metabolism by an INDETERMINATE DOMAIN transcription factor contributes to photoperiodic flowering in Arabidopsis. Plant J 65: 418-429

Shiu SH, Bleecker AB (2001) Receptor-like kinases from Arabidopsis form a monophyletic gene family related to animal receptor kinases. Proc Natl Acad Sci U S A 98: 10763-10768

Singh DP, Jermakow AM, Swain SM (2002) Gibberellins are required for seed development and pollen tube growth in Arabidopsis. The Plant cell 14: 3133-3147

Smakowska E, Kong J, Busch W, Belkhadir Y (2016) Organ-specific regulation of growth-defense tradeoffs by plants. Curr Opin Plant Biol 29: 129-137

Smith JM, Heese A (2014) Rapid bioassay to measure early reactive oxygen species production in Arabidopsis leave tissue in response to living Pseudomonas syringae. Plant Methods 10: 6 
Song JT (2006) Induction of a salicylic acid glucosyltransferase, AtSGT1, is an early disease response in Arabidopsis thaliana. Mol Cells 22: 233-238

Song JT, Koo YJ, Park JB, Seo YJ, Cho YJ, Seo HS, Choi YD (2009) The expression patterns of AtBSMT1 and AtSAGT1 encoding a salicylic acid (SA) methyltransferase and a SA glucosyltransferase, respectively, in Arabidopsis plants with altered defense responses. Mol Cells 28: 105-109

Spoel SH, Johnson JS, Dong X (2007) Regulation of tradeoffs between plant defenses against pathogens with different lifestyles. Proceedings of the National Academy of Sciences of the United States of America 104: 18842-18847

Stenzel I, Hause B, Miersch O, Kurz T, Maucher H, Weichert H, Ziegler J, Feussner I, Wasternack C (2003) Jasmonate biosynthesis and the allene oxide cyclase family of Arabidopsis thaliana. Plant Mol Biol 51: 895911

Strawn MA, Marr SK, Inoue K, Inada N, Zubieta C, Wildermuth MC (2007) Arabidopsis isochorismate synthase functional in pathogen-induced salicylate biosynthesis exhibits properties consistent with a role in diverse stress responses. J Biol Chem 282: 5919-5933

Sun J, Qi L, Li Y, Zhai Q, Li C (2013) PIF4 and PIF5 transcription factors link blue light and auxin to regulate the phototropic response in Arabidopsis. The Plant cell 25: 2102-2114

Sun T, Zhang Y, Li Y, Zhang Q, Ding Y, Zhang Y (2015) ChIP-seq reveals broad roles of SARD1 and CBP60g in regulating plant immunity. Nat Commun 6: 10159

Szklarczyk D, Franceschini A, Wyder S, Forslund K, Heller D, Huerta-Cepas J, Simonovic M, Roth A, Santos A, Tsafou KP, Kuhn M, Bork P, Jensen L, von Mering C (2015) STRING v10: protein-protein interaction networks, integrated over the tree of life. Nucleic Acids Res 43: D447-452

Tian T, Liu Y, Yan H, You Q, Yi X, Du Z, Xu W, Su Z (2017) agriGO v2.0: a GO analysis toolkit for the agricultural community, 2017 update. Nucleic Acids Res

Tsuda K, Katagiri F (2010) Comparing signaling mechanisms engaged in pattern-triggered and effectortriggered immunity. Curr Opin Plant Biol 13: 459-465

Ueguchi-Tanaka M, Ashikari M, Nakajima M, Itoh H, Katoh E, Kobayashi M, Chow TY, Hsing YI, Kitano H, Yamaguchi I, Matsuoka M (2005) GIBBERELLIN INSENSITIVE DWARF1 encodes a soluble receptor for gibberellin. Nature 437: 693-698

Van der Does D, Leon-Reyes A, Koornneef A, Van Verk MC, Rodenburg N, Pauwels L, Goossens A, Korbes AP, Memelink J, Ritsema T, Van Wees SC, Pieterse CM (2013) Salicylic acid suppresses jasmonic acid signaling downstream of SCFCOI1-JAZ by targeting GCC promoter motifs via transcription factor ORA59. The Plant cell 25: 744-761

van Verk MC, Bol JF, Linthorst HJ (2011) WRKY transcription factors involved in activation of SA biosynthesis genes. BMC Plant Biol 11: 89

Volz R, Heydlauff J, Ripper D, von Lyncker L, Gross-Hardt R (2013) Ethylene signaling is required for synergid degeneration and the establishment of a pollen tube block. Dev Cell 25: 310-316

Walley JW, Kelley DR, Nestorova G, Hirschberg DL, Dehesh K (2010) Arabidopsis deadenylases AtCAF1a and AtCAF1b play overlapping and distinct roles in mediating environmental stress responses. Plant Physiol 152: 866-875

Wang L, Czedik-Eysenberg A, Mertz RA, Si Y, Tohge T, Nunes-Nesi A, Arrivault S, Dedow LK, Bryant DW, Zhou W, Xu J, Weissmann S, Studer A, Li P, Zhang C, LaRue T, Shao Y, Ding Z, Sun Q, Patel RV, Turgeon R, Zhu X, Provart NJ, Mockler TC, Fernie AR, Stitt M, Liu P, Brutnell TP (2014) Comparative analyses of C(4) and $C(3)$ photosynthesis in developing leaves of maize and rice. Nat Biotechnol 32: 1158-1165

Wang L, Tsuda K, Truman W, Sato M, Nguyen le V, Katagiri F, Glazebrook J (2011) CBP60g and SARD1 play partially redundant critical roles in salicylic acid signaling. Plant J 67: 1029-1041

Wang X, Gao J, Zhu Z, Dong X, Wang X, Ren G, Zhou X, Kuai B (2015) TCP transcription factors are critical for the coordinated regulation of isochorismate synthase 1 expression in Arabidopsis thaliana. Plant $J$ 82: 151-162 
Wildermuth MC, Dewdney J, Wu G, Ausubel FM (2001) Isochorismate synthase is required to synthesize salicylic acid for plant defence. Nature 414: 562-565

Wu Y, Zhang D, Chu JY, Boyle P, Wang Y, Brindle ID, De Luca V, Despres C (2012) The Arabidopsis NPR1 protein is a receptor for the plant defense hormone salicylic acid. Cell Rep 1: 639-647

Xie C, Zhou X, Deng X, Guo Y (2010) PKS5, a SNF1-related kinase, interacts with and phosphorylates NPR1, and modulates expression of WRKY38 and WRKY62. J Genet Genomics 37: 359-369

Yamada S, Kano A, Tamaoki D, Miyamoto A, Shishido H, Miyoshi S, Taniguchi S, Akimitsu K, Gomi K (2012) Involvement of OsJAZ8 in jasmonate-induced resistance to bacterial blight in rice. Plant \& cell physiology 53: 2060-2072

Yamashino T, Nomoto Y, Lorrain S, Miyachi M, Ito S, Nakamichi N, Fankhauser C, Mizuno T (2013) Verification at the protein level of the PIF4-mediated external coincidence model for the temperatureadaptive photoperiodic control of plant growth in Arabidopsis thaliana. Plant Signal Behav 8: e23390

Yoo CY, Pence HE, Jin JB, Miura K, Gosney MJ, Hasegawa PM, Mickelbart MV (2010) The Arabidopsis GTL1 transcription factor regulates water use efficiency and drought tolerance by modulating stomatal density via transrepression of SDD1. Plant Cell 22: 4128-4141

Yoshida H, Hirano K, Sato T, Mitsuda N, Nomoto M, Maeo K, Koketsu E, Mitani R, Kawamura M, Ishiguro S, Tada Y, Ohme-Takagi M, Matsuoka M, Ueguchi-Tanaka M (2014) DELLA protein functions as a transcriptional activator through the DNA binding of the indeterminate domain family proteins. Proc Natl Acad Sci U S A 111: 7861-7866

Yoshida H, Ueguchi-Tanaka M (2014) DELLA and SCL3 balance gibberellin feedback regulation by utilizing INDETERMINATE DOMAIN proteins as transcriptional scaffolds. Plant Signal Behav 9: e29726

Zeng W, He SY (2010) A prominent role of the flagellin receptor FLAGELLIN-SENSING2 in mediating stomatal response to Pseudomonas syringae pv tomato DC3000 in Arabidopsis. Plant Physiol 153: 11881198

Zhang A, Ren HM, Tan YQ, Qi GN, Yao FY, Wu GL, Yang LW, Hussain J, Sun SJ, Wang YF (2016) S-type Anion Channels SLAC1 and SLAH3 Function as Essential Negative Regulators of Inward K+ Channels and Stomatal Opening in Arabidopsis. Plant Cell 28: 949-955

Zhang F, Yao J, Ke J, Zhang L, Lam VQ, Xin XF, Zhou XE, Chen J, Brunzelle J, Griffin PR, Zhou M, Xu HE, Melcher K, He SY (2015) Structural basis of JAZ repression of MYC transcription factors in jasmonate signalling. Nature 525: 269-273

Zhang HZ, Cai XZ (2005) [Nonexpressor of pathogenesis-related genes 1 (NPR1): a key node of plant disease resistance signalling network]. Sheng wu gong cheng xue bao = Chinese journal of biotechnology 21: 511-515

Zhang K, Halitschke R, Yin C, Liu CJ, Gan SS (2013) Salicylic acid 3-hydroxylase regulates Arabidopsis leaf longevity by mediating salicylic acid catabolism. Proc Natl Acad Sci U S A 110: 14807-14812

Zhang Y, Xu S, Ding P, Wang D, Cheng YT, He J, Gao M, Xu F, Li Y, Zhu Z, Li X, Zhang Y (2010) Control of salicylic acid synthesis and systemic acquired resistance by two members of a plant-specific family of transcription factors. Proc Natl Acad Sci U S A 107: 18220-18225

Zhang ZL, Ogawa M, Fleet CM, Zentella R, Hu J, Heo JO, Lim J, Kamiya Y, Yamaguchi S, Sun TP (2011) Scarecrow-like 3 promotes gibberellin signaling by antagonizing master growth repressor DELLA in Arabidopsis. Proceedings of the National Academy of Sciences of the United States of America 108: 21602165

Zheng XY, Spivey NW, Zeng W, Liu PP, Fu ZQ, Klessig DF, He SY, Dong X (2012) Coronatine promotes Pseudomonas syringae virulence in plants by activating a signaling cascade that inhibits salicylic acid accumulation. Cell Host Microbe 11: 587-596

Zheng XY, Zhou M, Yoo H, Pruneda-Paz JL, Spivey NW, Kay SA, Dong X (2015) Spatial and temporal regulation of biosynthesis of the plant immune signal salicylic acid. Proc Natl Acad Sci U S A 112: 91669173 
Zheng Y, Gao Z, Zhu Z (2016) DELLA-PIF Modules: Old Dogs Learn New Tricks. Trends in plant science 21: 813-815

Zhou JM, Trifa Y, Silva H, Pontier D, Lam E, Shah J, Klessig DF (2000) NPR1 differentially interacts with members of the TGA/OBF family of transcription factors that bind an element of the PR-1 gene required for induction by salicylic acid. Mol Plant Microbe Interact 13: 191-202

Zhou YP, Duan J, Fujibe T, Yamamoto KT, Tian CE (2012) AtIQM1, a novel calmodulin-binding protein, is involved in stomatal movement in Arabidopsis. Plant Mol Biol 79: 333-346

Zipfel C (2008) Pattern-recognition receptors in plant innate immunity. Curr Opin Immunol 20: 10-16

\section{Figure legends}

Figure 1: Dominant-negative idd4SRDX lines exhibit defense-related traits without infection. (A) Overview of 4 week-old WT, idd4SRDX1 and idd4SRDX2 line. Shoot fresh and dry weight are depicted in Fig. S1A-B.

(B) Lesion formation on the leaf surface of 14 day-old untreated idd4SRDX plants compared to WT

(C) 3,3'-Diaminobenzidine staining (DAB) to evaluate $\mathrm{H}_{2} \mathrm{O}_{2}$ levels in idd4SRDX lines in comparison to WT without infection/ treatment

(D) Lactophenol trypan blue (LTB) cell death staining of leaves without infection/ treatment

(E) Callose deposition assays on leaves of untreated idd4SRDX lines, orange arrows indicate callose spots (Fig. S1C). Scale bars $=3 \mathrm{~mm}$ (B-E).

(F) Overview of untreated stomata in WT, idd4SRDX1 and idd4SRDX2 line. Scale bar=100 $\mu \mathrm{m}$.

(G) Stomatal aperture was determined in untreated idd4SRDX lines and at $1 \mathrm{hr}$ and $4 \mathrm{hr}$ after PstDC3000 infection. Box plots show the interquartile range 25 to 75, and the inner square highlights the median, whiskers show the SEM, Statistical significance was analyzed by Student's test. Asterisks indicate significant differences n.s., non-significant, ${ }^{* *} p \leq 0.01$, ${ }^{* * *} p \leq 0.001$.

(H) flg22-dependent ROS production is significantly enhanced in the idd4SRDX lines. 36 leaf discs from 4 week-old plants were treated with water (mock-treated samples Fig. S1D) or $1 \mu \mathrm{M}$ flg22 over $45 \mathrm{~min}$. The data are shown as mean \pm SE.

(I) flg22-induced MAP kinase-activation assays in idd4SRDX1, GFP-IDD4 (IDD4ox) and WT plants. 14 day-old seedlings were treated with $1 \mu \mathrm{M}$ flg22 and samples were harvested at the indicated time points. Activation of MAP kinases 3 and 6 were analyzed by immunoblot using pTpY-antibody recognizing the MAPKs in their activated form. Protein loading control was performed by Ponceau S staining for Rubisco (RBC).

(J) Expression of the PTI-/ Defense markers FRK1 in idd4SRDX and IDD4ox lines without infection.

(K) Expression of WRKY33, WRKY22 and PR2 in the idd4SRDX lines without infection. Statistical significance was analyzed by Student's test. Letters above bars represent significance groups, $p \leq 0.05$.

Figure 2: Hormonal levels of salicylic acid and jasmonic acid are elevated in idd4SRDX lines (A, D) Quantitative analysis of free salicylic acid (SA) (A) and jasmonic acid (JA) (D) by using LC-MS/MS. Box plots are depicted for idd4SRDX lines and WT, boxes showing the interquartile range (IQR) $25^{\text {st }}$ to 
$75^{\text {th }}$ percentiles, inner ellipse representing the median, whiskers show the SEM, outliers are depicted by dots (Min/Max range).

(B-C) Genes involved in SA biosynthesis (S3H, ICS1, WRKY28, WRKY46, SARD1) and signaling (WRKY38) are up-regulated in untreated idd4SRDX lines compared to WT.

(E) Genes involved in JA-biosynthesis (ACO2) and response (PDF1.2, ERF1, ORA59) are up-regulated in untreated idd4SRDX lines compared to WT. Statistical significance was analyzed by Student's test. Letters above bars represent significance groups, $p \leq 0.05$.

Figure 3: Dominant-negative idd4SRDX mutants are more resistant to PstDC3000 and Botrytis cinerea infection.

(A-B) WT plants and idd4SRDX lines challenged by PstDC3000 (A) and PstDC3000 hrcC- (B), respectively. Plants, of three biological replicates $(n=30)$, were spray-inoculated with a bacterial suspension at $\mathrm{OD}_{600} 0.2$, the density of colony-forming units (cfu) was analyzed 2 and 72 hours post inoculation (hpi).

(C) WT plants and idd4SRDX lines challenged by Botrytis cinerea. Plants, of three biological replicates, were droplet-inoculated with a concentration of $5 \times 10^{6}$ spores $/ \mathrm{ml}$. Boxes represent the 25 th and 75 th percentiles, and the inner rectangle highlights the median, and outliers are depicted by dots (Min/Max range), whiskers show the SEM, and letters above boxes represent significance groups as determined by multiple comparison Student's test $p \leq 0.001$.

(D) WT plants, idd4SRDX1, idd4SRDX1/ SAGT1ox, and SAGT1ox lines were treated by Pst DC3000 hrcC-. Expression of SAGT1ox in idd4SRDX1 lines reconstitutes WT-like susceptibility to infection. Plants were spray-inoculated with a bacterial suspension at $\mathrm{OD}_{600} 0.2$. Statistical significance was analyzed by Student's test. Letters above bars represent significance groups, $p \leq 0.05$.

(E) Overview of WT plants, idd4SRDX1, idd4SRDX1/ SAGT1ox, and SAGT1ox lines. DAB-staining shows that the hydrogen peroxide levels are significantly reduced in idd4SRDX2/SAGT10x in comparison to idd4SRDX lines (quantification Figure S2 B). Scale bar, $7.5 \mathrm{~mm}$.

(F) Quantitative analysis of salicylic acid by LC-MS/MS depicted as box plots for WT, idd4SRDX1, idd4SRDX1/SAGT10x, and SAGT10x, boxes representing the 25th and 75th percentiles and the inner rectangle highlights the median, whiskers show the SEM, and outliers are depicted by dots (Min/Max range).

Figure 4: Transcriptome composition of idd4SRDX lines.

(A-B) Depicted are scatter plots of whole-genome transcript fragments per kilobase of transcript per million mapped reads (FPKM) in WT (Col0) vs. idd4SRDX (A) or WT (mock) vs. WT (1h, flg22) (B).

(C) $\log _{2}$ distribution of up- and down-regulated genes in idd4SRDX lines, $p \leq 0.01$ (Table S2)

(D) Transcriptome composition of up-regulated genes in idd4SRDX shows high overlap with genomewide transcriptome data of 14 day-old WT plants treated with flg22 for $1 \mathrm{~h}$. 39,6 \% of up-regulated genes in idd4SRDX overlap with those in flg22-treated WT plants.

(E) Significantly enriched GO terms of idd4SRDX up-regulated genes (Table S1)

(F) Significantly enriched GO categories among up-regulated genes of the overlap between idd4SRDX and flg22-treated WT plants (Table S3).

Figure 5: Functional categorization of primary IDD4 target genes and differentially regulated genes in idd4SRDX.

(A) Subcellular localization of GFP:IDD4:SRDX in the nucleus of Arabidopsis.

(B) Genome-wide binding study of IDD4, provided by O'Malley et al. 2016, revealed the most frequent enrichment of the ID1-cis motif in the IDD4 target sequences. The ID1 motif consists of the core sequence A/C/GGACAA.

(C-F, J-L ) Genome-wide binding study of IDD4 (O'Malley et al. 2016) revealed binding profiles of IDD4 to selected target sequences of GA3OX1 (C), ATH1 (D), GID1B (E), SCL3 (F), WRKY27 (J), STOMAGEN $(\mathrm{K})$ and SPEECHLESS (L). The blue arrows depict significant IDD4 binding regions. The distribution of 
the variable core ID1-motif in the gene-body and the 5' upstream and 3'-downstream sequence of each gene is indicated in a color-code. The TAIR annotations of the genomic loci are shown at the bottom of each panel. The genomic locus indicated above the scale represents forward orientation, while the one below represents reverse orientation.

(G) Expression of GID1B in idd4SRDX, without treatment and $1 \mathrm{hr}$ after flg22 application. Error bars show \pm SEM; statistical significance was analyzed by Student's test, letters above bars represent significant groups $p \leq 0.05$.

$(\mathbf{H}, \mathbf{M})$ Transcriptome composition of differentially-regulated genes in idd4SRDX $(p<0.01)$ contribute to Gibberellin-signaling/ response (H) and Stomatal patterning/ aperture (M).

$(\mathbf{I}, \mathbf{N})$ Protein-interaction networks derived from the genome-wide binding study of IDD4 (O'Malley et al. 2016) and differentially-regulated genes in idd4SRDX. All significant target genes were pooled and used to generate a network using STRING (version 10.0). Meaning of network edges "evidence".

Figure 6: Functional categorization of differentially regulated genes in idd4SRDX by taking into account primary IDD4 target genes.

(A) Transcriptome composition of differentially-regulated genes in idd4SRDX $(p<0.01)$ contribute to Auxin transport/ signaling.

(B-D, H)) Genome-wide binding study of IDD4 (O'Malley et al. 2016) revealed binding profiles of IDD4 to selected target sequences of PIN5 (B), PIN-LIKES 3 (C), IAA24 (D) and CAF1a (H). The blue arrows depict significant IDD4 binding regions. The distribution of the variable core ID1-motif in the gene-body and the 5'-upstream and 3'-downstream sequence of each gene is indicated in a color-code. The genomic locus indicated above the scale represents forward orientation, while the one below represents reverse orientation.

(E) Protein interaction networks derived from the genome-wide binding study of IDD4 (O'Malley et al. 2016) and differentially-regulated genes in idd4SRDX. All significant target genes were pooled and used to generate a network using STRING (version 10.0). Meaning of network edges "evidence".

(F-G) Expression of AP2C1 (F) and CAF1a (G) in idd4SRDX and IDD4ox lines. Error bars show \pm SEM; statistical significance was analyzed by Student's test against WT. Asterisks indicate significant differences ${ }^{*} p \leq 0.05,{ }^{* *} p \leq 0.01,{ }^{* * *} p \leq 0.001$; n.s, non-significant.

Figure S1. idd4SRDX lines have reduced fresh and dry weight and exhibit callose spots without infection.

(A-B) Fresh and dry weight is significantly reduced in idd4SRDX1, -2 compared to WT.

(C) Without flg22-treatment and under sterile conditions on sugar-lacking MS medium, idd4SRDX lines exhibit spontaneous callose depositions on the leaf surface. Statistical significance was analyzed by using Student's t-test against WT control ${ }^{* * *} \mathrm{P} \leq 0.001$ (Figure 3E).

(D) Mock-treated ROS burst assay of WT, iddSRDX1, idd4SRDX2 lines (refers to Figure 3H).

Statistical significance was analyzed by Student's test. Asterisks indicate significant differences compared to $\mathrm{WT},{ }^{* * *} p \leq 0.001$.

Figure S2: Characterization of idd4SRDX2/SAGT1ox lines.

(A) The perimeter of WT, idd4SRDX1, idd4SRDX1/SAGT10x and SAGT1ox lines of 4 week-old plants. Notch boxes show the interquartile range 25 to 75 , and the inner rectangle highlights the median, whiskers show the SEM, and outliers are depicted by dots (Min/Max range)

(B) DAB staining intensity of WT, idd4SRDX1, idd4SRDX1/SAGT1ox and SAGT1ox lines of 14 day-old plants. Notch boxes show the interquartile range 10 to 90 , and the inner rectangle highlights the median, whiskers show the SEM, and outliers are depicted by dots (Min/Max range).

(C) Expression of IDD4SRDX in idd4SRDX1 and idd4SRDX1/SAGT10x lines. The expression was tested by the use of the primer 352s, which binds on IDD4, and primer 251as that binds on SRDX sequence.

(A-B) Statistical significance was analyzed by Student's test. Letters above bars represent significance groups, $p \leq 0.05$. 
Table S1: GO term analysis of up- and down-regulated genes in idd4SRDX lines

Table S2: Overview of differentially regulated genes in idd $4 S R D X$ line

Table S3: Overview of commonly up-regulated genes and corresponding GO term analysis of untreated idd4SRDX lines and flg22-treated WT plants.

Table S4: Differentially expressed genes in WT plants, $1 \mathrm{hr}$ after flg22-treatment.

Table S5: Components of the SA, JA and ethylene metabolism and signaling pathway are differentially expressed in idd4SRDX lines.

Table S6: Differentially expressed genes in idd4SRDX that are considered as major IDD4 downstream targets by O'Malley, Huang, et al. 2016 

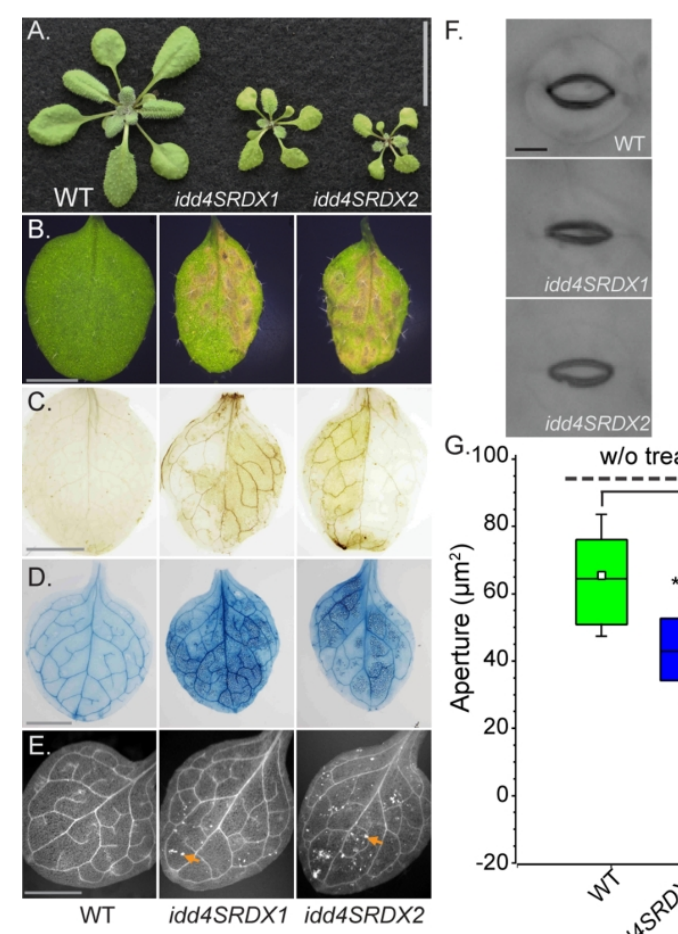

$\mathrm{H}$.

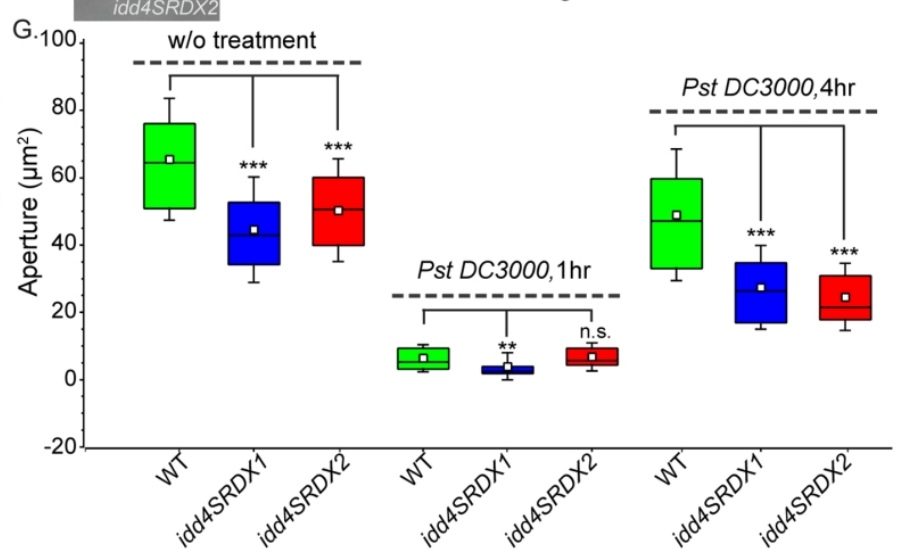

I.
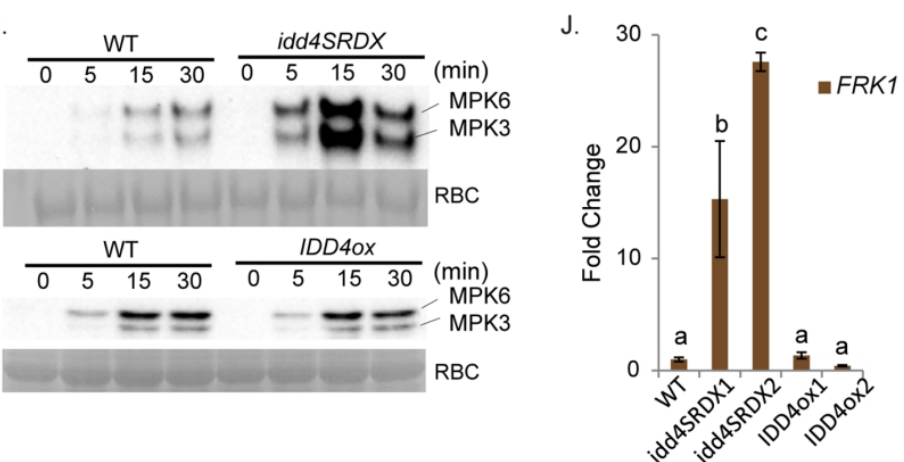

K. $\quad \begin{array}{ll}\mathrm{WT} \\ & =i d d 4 S R D \times 1\end{array}$
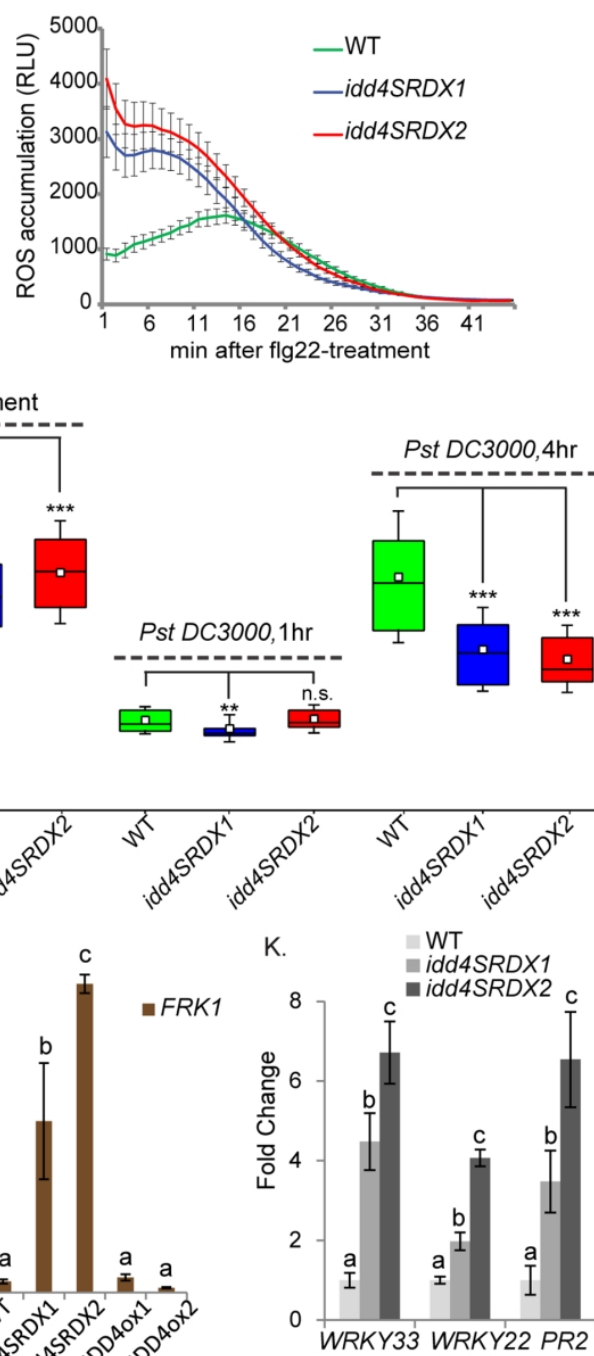


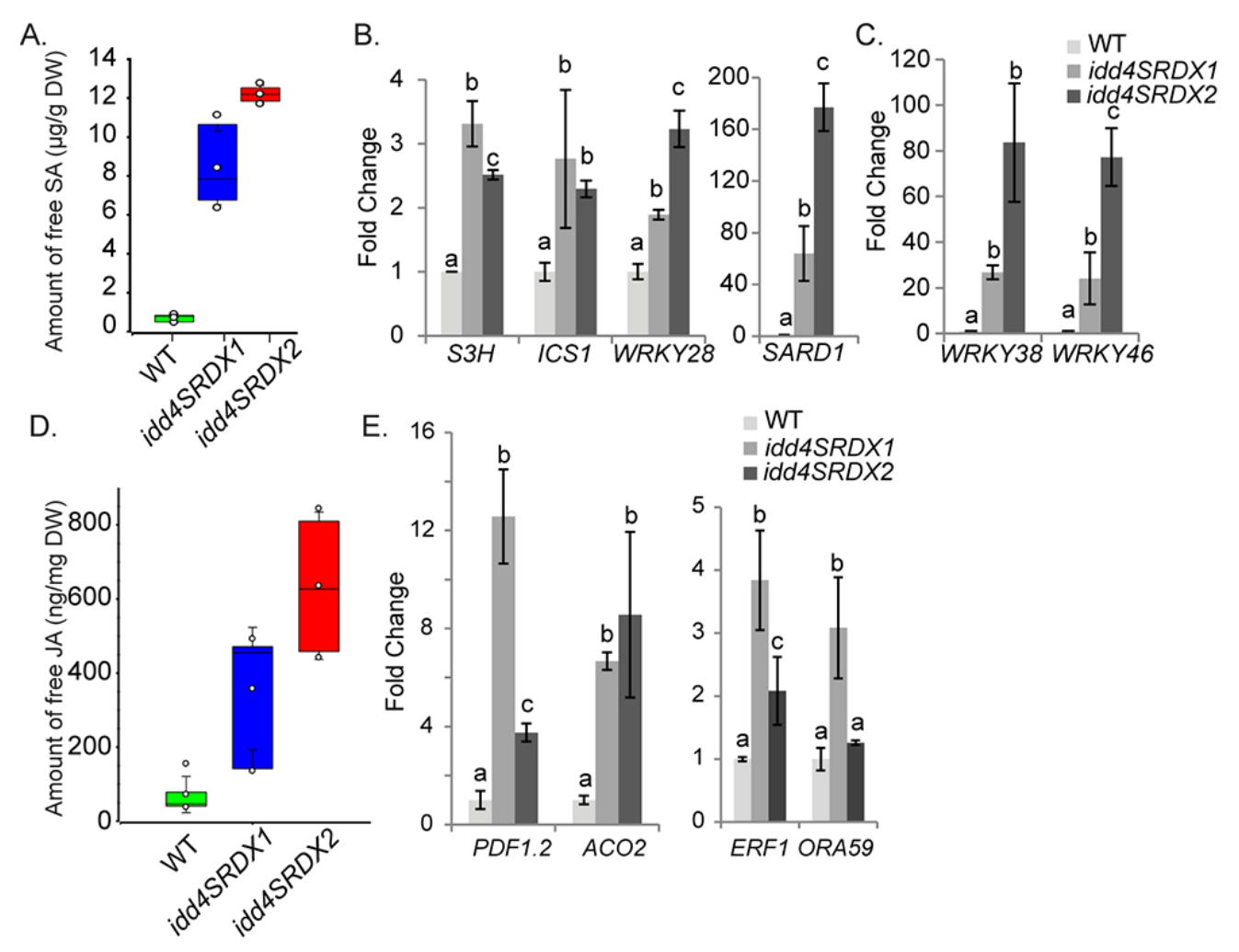



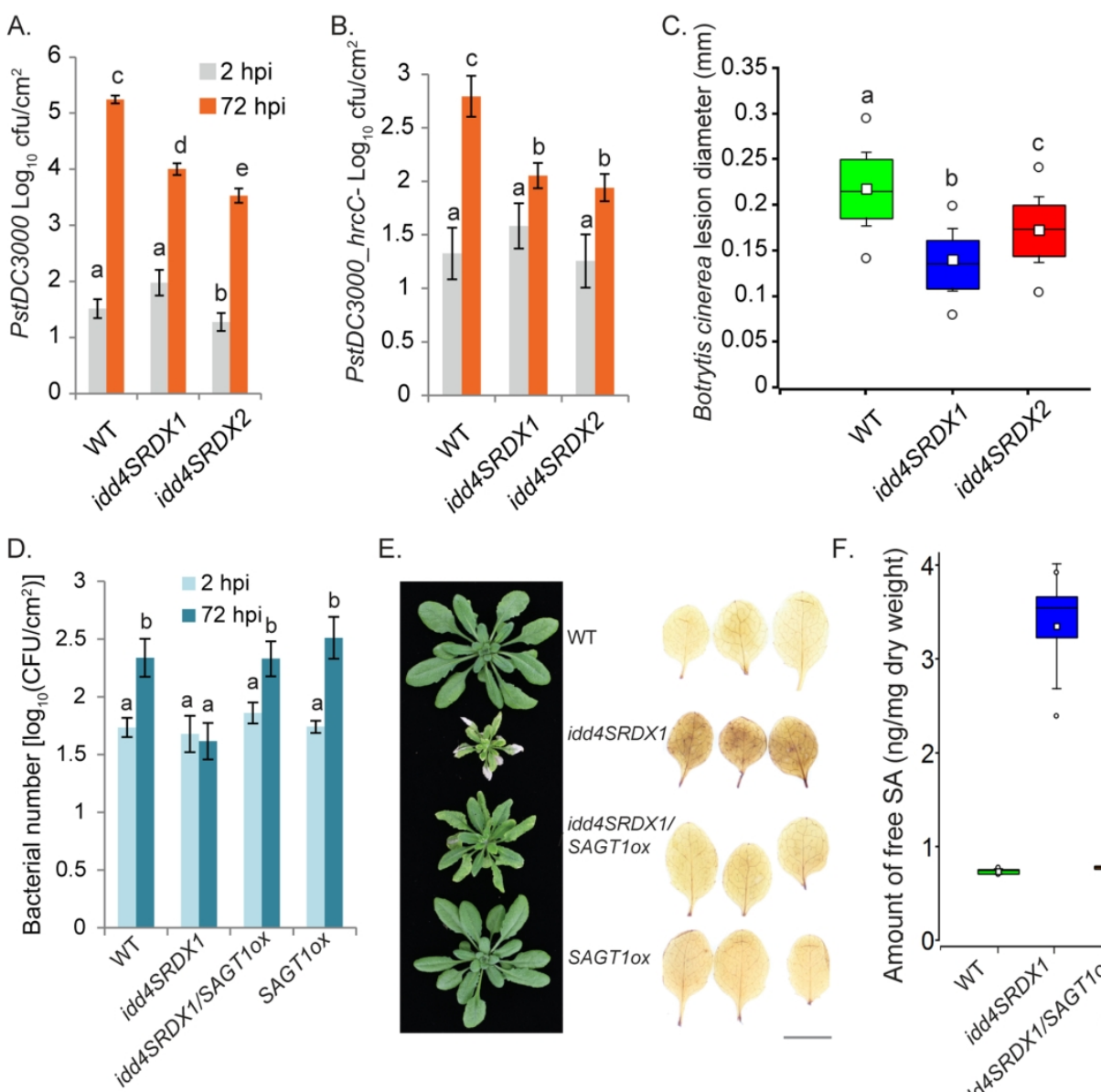

E.
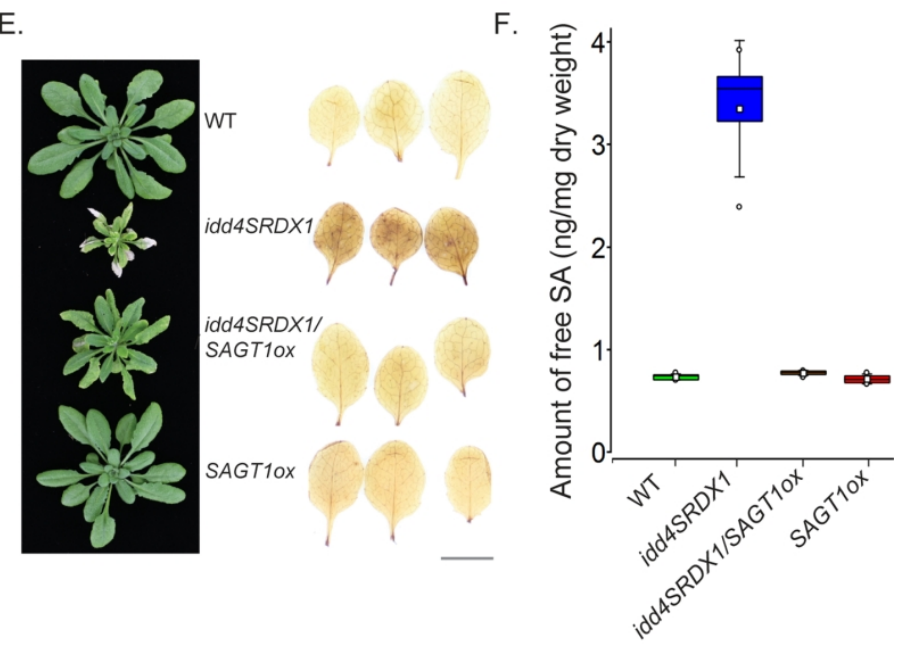

$173 \times 161 \mathrm{~mm}(300 \times 300 \mathrm{DPI})$ 
A.

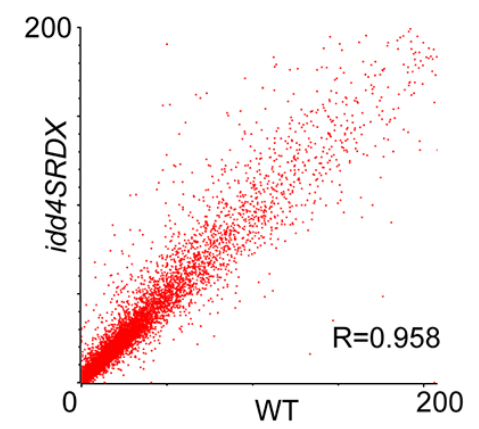

C. Transcriptome analysis (WT vs. idd4SRDX)

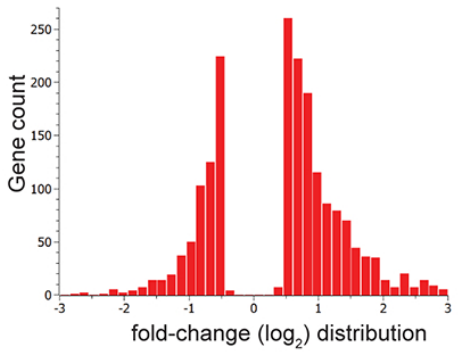

B.

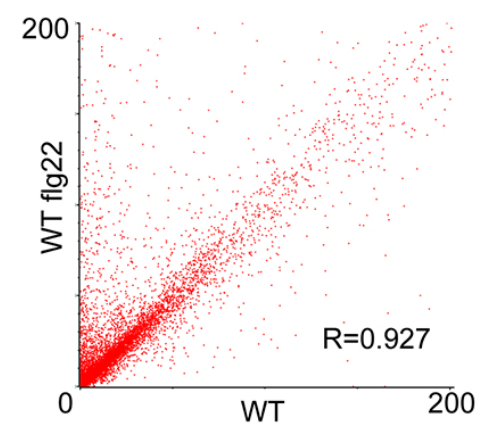

D.

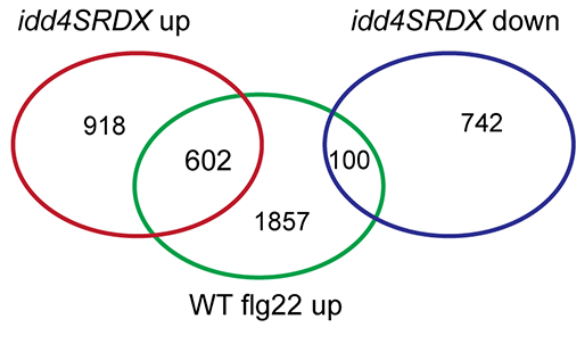

E.

\begin{tabular}{|l|l|c|}
\hline GO term & Description & p-value \\
\hline GO:0006952 & defense response & $2.50 \mathrm{E}-83$ \\
\hline GO:0045087 & innate immune response & $4.60 \mathrm{E}-66$ \\
\hline GO:0009627 & systemic acquired resistance & $9.70 \mathrm{E}-52$ \\
\hline GO:0071446 & cellular response to salicylic acid stimulus & $4.20 \mathrm{E}-41$ \\
\hline GO:0009626 & plant-type hypersensitive response & $1.00 \mathrm{E}-38$ \\
\hline GO:0043067 & ethylene metabolic process & $4.50 \mathrm{E}-15$ \\
\hline GO:0007243 & salicylic acid metabolic process & $3.90 \mathrm{E}-37$ \\
\hline GO:0002679 & respiratory burst during defense response & $7.20 \mathrm{E}-25$ \\
\hline GO:0006800 & oxygen and reactive oxygen species metabolic process & $1.20 \mathrm{E}-20$ \\
\hline GO:0052542 & jasmonic acid metabolic process & $6.80 \mathrm{E}-06$ \\
\hline GO term & Description & p-value \\
\hline GO:0006952 & defense response & $7.30 \mathrm{E}-105$ \\
\hline GO:0045087 & innate immune response & $3.20 \mathrm{E}-90$ \\
\hline GO:0009751 & ethylene metabolic process & $4.50 \mathrm{E}-22$ \\
\hline GO:0009697 & salicylic acid biosynthetic process & $2.30 \mathrm{E}-49$ \\
\hline GO:0009607 & jasmonic acid biosynthetic process & $6.50 \mathrm{E}-05$ \\
\hline GO:0009626 & plant-type hypersensitive response & $3.40 \mathrm{E}-47$ \\
\hline
\end{tabular}




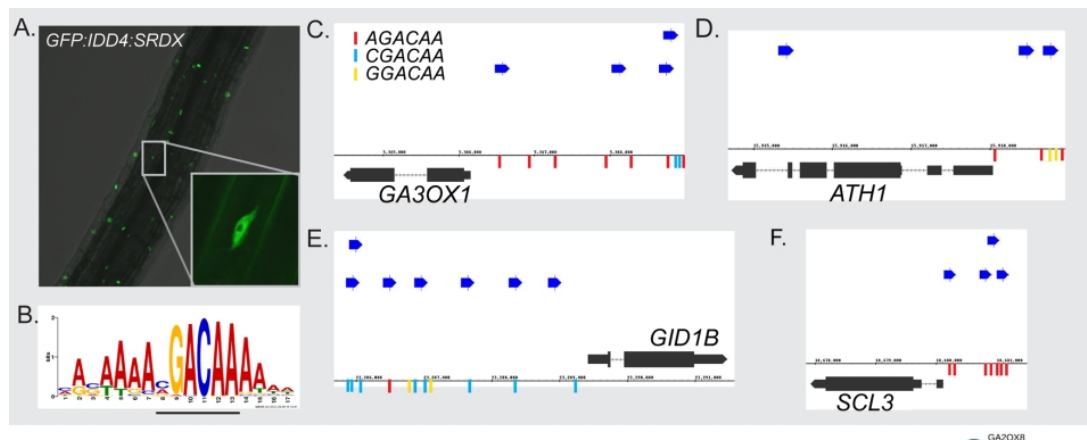

G.

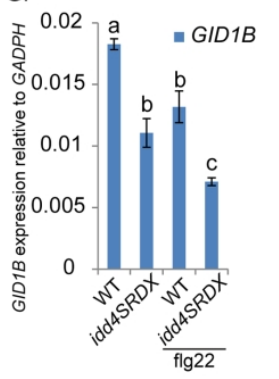

H.

De-regulated genes in idd4SRDX/ WT, $p<0.01$ Locus $\quad \log _{2}$ Annotation AT3G63010 $-0.52 \quad$ GID1B $\begin{array}{lll}\text { AT3G63010 } & -0.52 & \text { GID1B } \\ \text { AT1G15550 } & -0.46 & \text { GA3OX1 }\end{array}$ $\begin{array}{lll}\text { AT1G15550 } & -0.46 & \text { GA3OX } \\ \text { AT4G32980 } & -0.47 & \text { ATH1 }\end{array}$ $\begin{array}{lll}\text { AT4G32980 } & -0.47 & \text { ATH1 } \\ \text { AT1G50420 } & -0.91 & \text { SCL3 }\end{array}$ $\begin{array}{lrl}\text { AT1G50420 } & -0.91 & \text { SCL3 } \\ \text { AT5G56300 } & 4.69 & \text { GAMT2 }\end{array}$ $\begin{array}{lll}\text { AT5G56300 } & 4.69 & \text { GAMT2 } \\ \text { AT1G30040 } & 0.89 & \text { GA2OX2 }\end{array}$ $\begin{array}{lll}\text { AT1G30040 } & 0.89 & \text { GA2OX2 }\end{array}$ $\begin{array}{lll}\text { AT1G02400 } & 1.91 \quad \text { GA2OX6 }\end{array}$ $\begin{array}{lll}\text { AT } 4 G 21200 & 1.11 \quad \text { GA2OX8 }\end{array}$ $\begin{array}{lll}\text { AT5G51810 } & 1.38 \quad \text { GA2OOX2 }\end{array}$ $\begin{array}{lll}\text { AT5G17490 } & 1.33 & R G L 3 \\ \text { AT1G66350 } & 1.19 & \text { RGL1 }\end{array}$ \begin{tabular}{lll} 
AT1G66350 & $1.19 \quad$ RGL1 \\
\hline
\end{tabular}

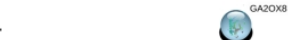

Gibberellinsignaling/ response

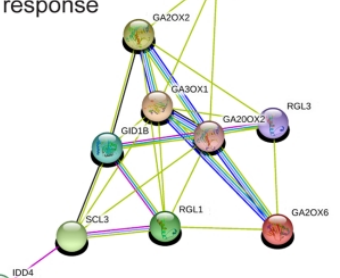
$0^{1004}$

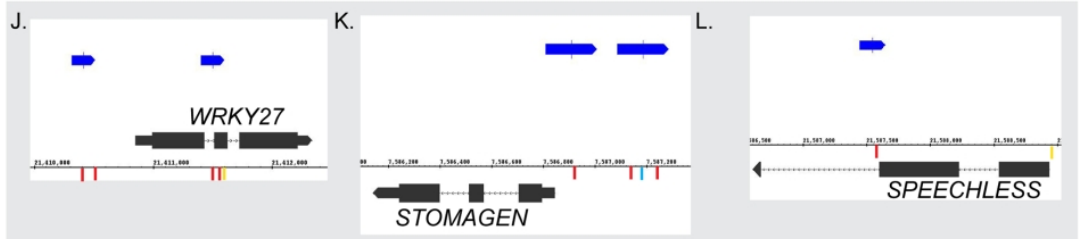

M. De-regulated genes in idd4SRDX/ WT, $p<0.01 \quad \mathrm{~N}$.

\begin{tabular}{llll} 
& Locus & $\log _{2}$ & Annotation \\
\hline \multirow{2}{*}{ Immune- } & AT2G30020 & -0.45 & AP2C1 \\
modulators & AT3G44260 & -0.86 & CAF1a \\
& AT5G52830 & -0.69 & WRKY27 \\
\hline & AT4G12970 & -0.92 & STOMAGEN \\
& AT5G53210 & -1.01 & SPEECHLESS \\
& AT5G65420 & -0.90 & CYCD4 \\
Stomatal & AT1G34245 & -1.66 & EPF2 \\
patterning/ & AT3G06120 & -1.86 & MUTE \\
aperature & AT4G18290 & -2.14 & KAT2 \\
& AT1G04110 & -0.96 & SDD1 \\
& AT4G33050 & 0.56 & EDA39 \\
& AT1G12110 & 0.63 & NRT1.1 \\
& AT2G40180 & 1.93 & PP2C5 \\
& AT3G11820 & 0.76 & SYP121 \\
\hline
\end{tabular}

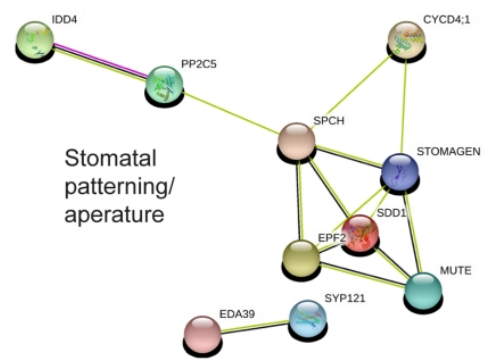


A.

\begin{tabular}{|c|c|c|}
\hline \multicolumn{3}{|c|}{ De-regulated genes in idd $4 S R D X / W T, p<0.01$} \\
\hline Locus & $\log _{2}$ & Annotation \\
\hline AT1G76520 & -0.61 & PIN-LIKES 3 \\
\hline AT3G53480 & -0.51 & $A B C C 12$ \\
\hline AT1G19850 & -0.51 & MONOPTEROS (MP/IAA24) \\
\hline AT1G04240 & -0.59 & IAA3 \\
\hline AT5G16530 & -1.28 & PIN5 \\
\hline AT3G18010 & -0.85 & WOX1 \\
\hline AT4G27260 & 1.02 & WES1 IAA-amido synthase \\
\hline AT5G54510 & 0.84 & DFL1 IAA-amido synthase \\
\hline AT1G19220 & 0.64 & ARF19 \\
\hline AT3G59900 & 1.57 & ARGOS \\
\hline AT3G15540 & 2.00 & IAA19 \\
\hline AT1G23080 & 0.78 & PIN19 \\
\hline
\end{tabular}

E.

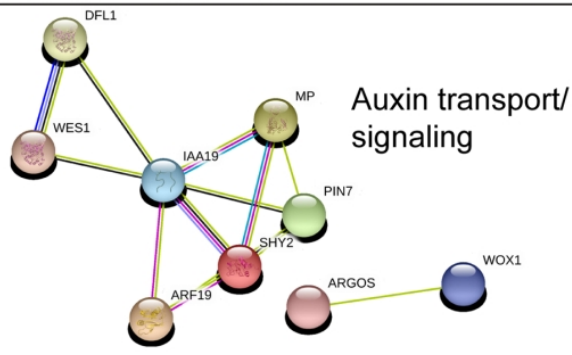

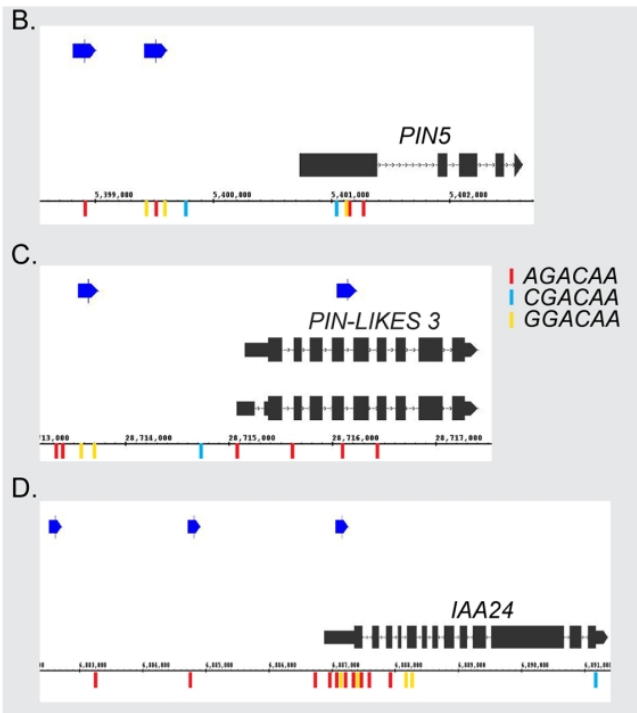

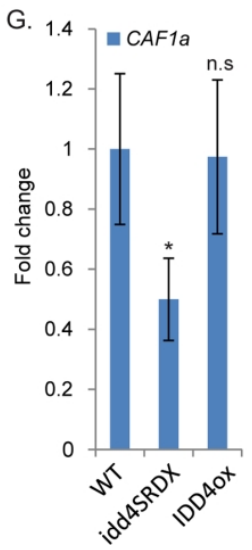

$\mathrm{H}$.

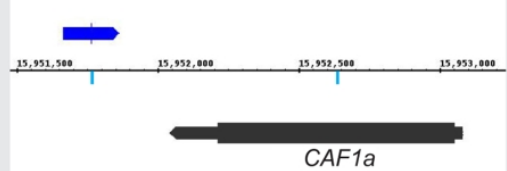

